\title{
Emerging roles of interferon-stimulated genes in the innate immune response to hepatitis $\mathrm{C}$ virus infection
}

\author{
Mun-Teng Wong ${ }^{1,3}$ and Steve S-L Chen ${ }^{1,2,3}$
}

Infection with hepatitis C virus (HCV), a major viral cause of chronic liver disease, frequently progresses to steatosis and cirrhosis, which can lead to hepatocellular carcinoma. HCV infection strongly induces host responses, such as the activation of the unfolded protein response, autophagy and the innate immune response. Upon HCV infection, the host induces the interferon (IFN)-mediated frontline defense to limit virus replication. Conversely, HCV employs diverse strategies to escape host innate immune surveillance. Type I IFN elicits its antiviral actions by inducing a wide array of IFN-stimulated genes (ISGs). Nevertheless, the mechanisms by which these ISGs participate in IFN-mediated anti-HCV actions remain largely unknown. In this review, we first outline the signaling pathways known to be involved in the production of type I IFN and ISGs and the tactics that HCV uses to subvert innate immunity. Then, we summarize the effector mechanisms of scaffold ISGs known to modulate IFN function in HCV replication. We also highlight the potential functions of emerging ISGs, which were identified from genome-wide siRNA screens, in HCV replication. Finally, we discuss the functions of several cellular determinants critical for regulating host immunity in HCV replication. This review will provide a basis for understanding the complexity and functionality of the pleiotropic IFN system in HCV infection. Elucidation of the specificity and the mode of action of these emerging ISGs will also help to identify novel cellular targets against which effective HCV therapeutics can be developed.

Cellular \& Molecular Immunology (2016) 13, 11-35; doi:10.1038/cmi.2014.127; published online 29 December 2014

Keywords: anti-HCV activity; HCV; IFN; innate immunity; ISG

\section{INTRODUCTION}

Hepatitis $\mathrm{C}$ virus (HCV) infects more than 170 million people worldwide and represents a heavy burden to global health, with the highest prevalence rates found in Africa and the Eastern Mediterranean. ${ }^{1}$ Acute HCV infection is asymptomatic, and in $70 \%$ of infected individuals, the virus persists and progresses to chronic liver diseases, including fibrosis, steatosis, cirrhosis and hepatocellular carcinoma. ${ }^{2,3}$ Furthermore, HCV is a major cause of type I mixed cryoglobulinemia, which occurs in $10 \%$ of patients. ${ }^{4}$

Using the HCV genotype 2a isolate Japanese fulminant hepatitis-1 genome-based cell culture-derived infectious HCV (HCVcc), ${ }^{5}$ Zhong et al. ${ }^{6}$ demonstrated that HCV and cells coevolve in vitro during chronically persistent infection, which involves the selection of viral mutants with increased infectivity and cells with resistance to viral entry and/or RNA replication. In this coevolution process, HCV exhibits multifaceted interactions with the host cells, and these cellular stress responses subsequently affect virus replication. For instance, infection with HCVcc or expression of the Japanese fulminant hepatitis-1 genome has been shown to trigger cytopathic effects, endoplasmic reticulum (ER) stress, the unfolded protein response (UPR), autophagy and the innate immune response. ${ }^{7-14}$

In the competition between this virus and host cells, viral infection often triggers a first-line host defense through the production of type I interferon (IFN), which is a broadly acting antiviral cytokine, and inflammatory cytokines. These cytokines confer an antiviral state on the host cells, thereby interfering with viral replication. ${ }^{15,16}$ With the ability to enhance the immune response for virus clearance or to inhibit viral replication, IFN-based therapies have been used to treat HCVinfected patients for over two decades. ${ }^{17}$

To guard against viral infection, the host cell has developed multiple restriction strategies to limit viral infection. The

${ }^{1}$ Institute of Biomedical Sciences, Academia Sinica, Taipei and ${ }^{2}$ Ph.D. Program in Translational Medicine, Kaohsiung Medical University and Academia Sinica

${ }^{3}$ MTW and SSC contributed equally to this manuscript.

Correspondence: Dr SSL Chen, Institute of Biomedical Sciences, Academia Sinica, 128 Yen-Chiu-Yuan Road, Section 2, Nan-Kang, Taipei.

E-mail: schen@ibms.sinica.edu.tw

Received: 22 August 2014; Revised: 21 November 2014; Accepted: 22 November 2014 
expression of many of these restriction factors is subject to transcriptional regulation by IFN. ${ }^{13,14}$ Upon infection by viruses such as HCV, viral RNA is first sensed by cellular pattern recognition receptors (PRRs), and the PRR-mediated recruitment of adaptor proteins and the activation of downstream signaling lead to IFN production. ${ }^{16,18,19}$ After binding to its receptor (IFNAR) complex present on the cell surface, IFN triggers the Janus kinase (JAK)/signal transducer and activator of transcription (STAT) pathway to drive the synthesis of over 300 IFN-stimulated genes (ISGs), which block virus replication at different phases of the virus replication cycle. $^{19-22}$ These ISGs are usually not synthesized at the basal state, but are induced to express and mediate the antiviral effector functions of IFN upon viral infection or IFN treatment.

In response, viruses have developed elaborate strategies to escape the IFN antiviral system by blocking the expression or antiviral functions of IFN. ${ }^{19,23,24}$ Therefore, the host and HCV maintain a homeostatic state, allowing tightly restricted viral replication without killing the host. ${ }^{13,25-27}$ Recent studies on genome-wide siRNA screens have also added new candidates to this growing list of anti-HCV ISGs. These findings highlight the complexity and pleiotropic roles of IFN and its induced ISGs in modulating innate immunity and virus replication. Nevertheless, the complete spectrum of ISGs and their functionality in suppressing HCV replication have yet to be defined. ${ }^{28,29}$

In this review, we focus on the molecular aspects of the type I IFN system and its effector mechanisms in modulating HCV replication. First, we briefly discuss the signaling triggered by the retinoic acid-inducible gene 1-like receptor (RLR) and the Toll-like receptor (TLR), which leads to type I IFN synthesis and IFN-mediated signaling pathway activation, resulting in the expression of a variety of effector ISGs. We also summarize the strategies that HCV uses to escape IFN antiviral surveillance. Additionally, we highlight what is currently known regarding the pivotal ISGs in viral infections, with an emphasis on their anti-HCV activities, and the emerging ISGs identified from recent genome-wide siRNA screens in relation to anti$\mathrm{HCV}$ activities. Finally, we discuss the potential functions of several critical cellular factors, such as high-mobility group box 1 (HMGB1) and immunity-related GTPase family M (IRGM), and cellular pathways, such as UPR and autophagy, during $\mathrm{HCV}$ infection. Although these cellular determinants are not stimulated by IFN, these factors critically control the host immune response. Therefore, these determinants may also play crucial roles in modifying HCV replication.

This review provides a perspective for a better understanding of the anti-HCV mechanisms of IFN, ISGs and several critical cellular determinants known to contribute to the regulation of innate immunity. The gathered information not only provides a clearer picture for the specificity, functionality and complexity of the IFN system and its effector mechanisms in the control of HCV infection, but also helps to identify novel cellular targets against which efficacious therapeutic strategies can be developed. Clinically, the identification of new ISGs will also help to optimize the current IFN-based therapy and to provide a basis for more accurate predictions of IFN treatment outcomes.

\section{HCV GENOTYPES AND RESPONSE TO IFN TREATMENT}

$\mathrm{HCV}$ is an enveloped, positive-sense, single-stranded RNA virus classified within the genus hepacivirus in the Flaviviridae family. ${ }^{3}$ Currently, $\mathrm{HCV}$ isolates are classified into seven major genotypes, i.e., genotypes 1 through 7 , and an array of subtypes. ${ }^{30} \mathrm{HCV}$ genotypes differ by $20 \%-35 \%$ in genome sequence, ${ }^{31}$ whereas subtypes within each genotype can differ by least $15 \%{ }^{30}$ Genotype 1 is the most prevalent (46\%), followed by genotype $3(30 \%)$; genotypes 2, 4 and 6 (cumulatively approximately 22\%); and genotype 5 (less than $1 \%$ ). ${ }^{32}$ Different genotypes exhibit distinct geographic distributions. Genotype 1 predominates in America and Europe, genotype 2 in Japan, genotype 3 in Asia, genotype 4 in Africa and Middle East and genotype 6 in Southeast Asia. ${ }^{32}$ HCV is transmitted via blood transfusion, intravenous drug abuse, unsafe therapeutic injection, liver transplantation and other risk factors. ${ }^{33}$

The combination of PEGylated IFN- $\alpha$ and ribavirin is the standard therapy for HCV infection. However, this treatment is associated with side effects, and the efficacy of this regimen varies among genotypes, limiting the success rate of this treatment. ${ }^{34}$ Compared with genotype 2 , infection with genotypes $1 \mathrm{a}$ and $\mathrm{lb}$ results in more severe liver disease and low responsiveness to IFN therapy. Seventy-one percent of patients with genotype 2 infection respond to IFN therapy, whereas only $28 \%$ of genotype $1 \mathrm{a}$ and $26 \%$ of genotype $1 \mathrm{~b}$ show a response. ${ }^{35}$ Patients infected with genotype 6 generally show higher sustained virological responses to IFN therapy than genotype 1infected patients, ${ }^{36}$ whereas genotype 3 -infected patients show a lower sustained virological response compared with genotype 1-infected patients. ${ }^{37}$ The heterogeneity of HCV genotypes also translates to differences in the manifestation of liver disease. ${ }^{38}$ For example, hepatic steatosis is most common in patients infected with genotype 3 and is attributed to its core protein. ${ }^{37}$ Recently, the use of active direct-acting antiviral molecules to block HCV infection has led to substantial improvements in sustained virological response rates in genotype 1-infected patients. However, the use of these drugs may allow selection of resistant variants if direct-acting antiviral monotherapy is adopted, and a high relapse rate occurs after direct-acting antiviral treatment is discontinued. ${ }^{39}$

\section{HCV REPLICATION}

The approximately 9.6-kb HCV genome contains a single open reading frame flanked by untranslated regions (UTRs) at its $5^{\prime}$ and $3^{\prime}$ ends (Figure 1). ${ }^{3}$ The internal ribosome entry site (IRES) located in the $5^{\prime}$-UTR directs cap-independent translation, whereas the $3^{\prime}$-UTR contains sequences critical for viral replication and translation. ${ }^{40}$ The $3^{\prime}$-UTR (positioned at nucleotides 9389-9679 of the HCV genome) contains a poly(U/UC) (PU/UC) tract located at nucleotide positions 9436-9600, which was identified as an HCV pathogen-associated molecular pattern (PAMP) that triggers RLR-mediated type I IFN production (Figure 1). ${ }^{22}$ Translation of the HCV genomic 


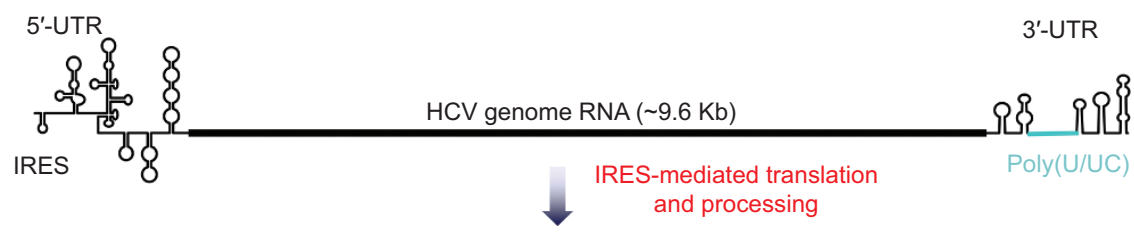

Polyprotein $(\sim 3,000$ amino acids)

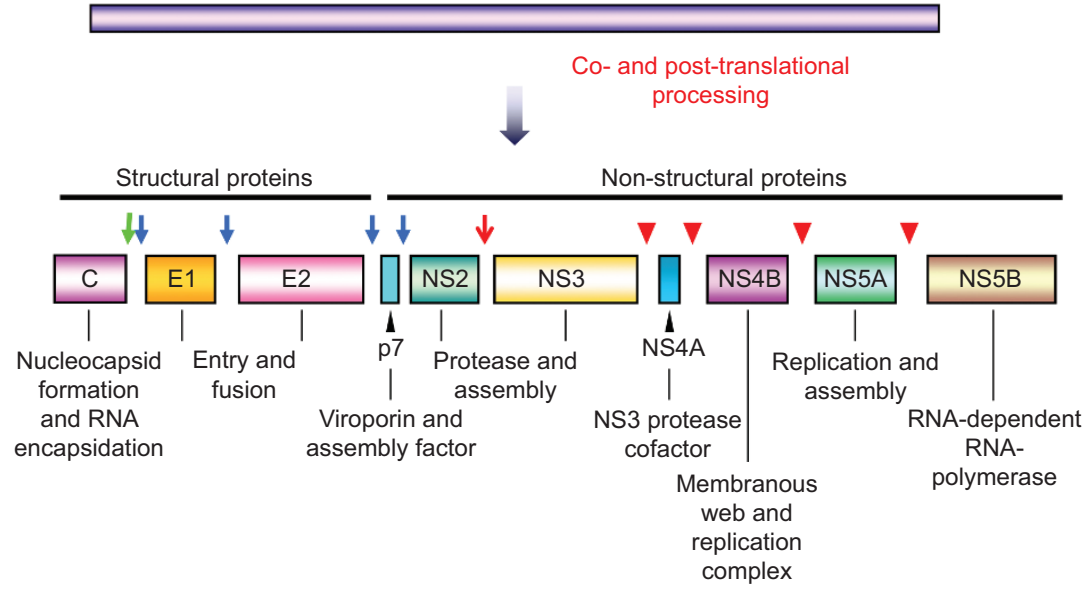

Figure 1 HCV genome organization and encoded viral proteins. The HCV genome, which consists of a 9.6-kb open reading frame with 5' - and 3'UTRs, is translated using an IRES to produce a polyprotein of approximately 3000 amino acids. Cellular and viral proteases mediate the proteolytic cleavage of the polyprotein into three structural proteins, core, E1 and E2, and the non-structural proteins p7, NS2, NS3, NS4A, NS4B, NS5A and NS5B. The sites cleaved by cellular signal peptidase, signal peptide peptidase, and NS3/NS4A protease are marked by blue and green arrows, and red arrowheads, respectively, whereas the NS2/NS3 autoproteolytic site is indicated with a red arrow. Core, E1 and E2 form the virion. NS2 and p7 participate in the assembly of viral particles. NS3, NS4Band NS5A are critical for both viral replication and assembly, whereas NS4A and NS5B function in viral replication. The PU/UC tract located in the $3^{\prime}$-UTR is also marked. HCV, hepatitis C virus; NS, non-structural protein; UTR, untranslated region.

RNA produces a single polyprotein of approximately 3000 amino acids, which is further processed by cellular and viral proteases to yield the structural proteins core, E1 and E2 and the non-structural (NS) proteins p7, NS2, NS3, NS4A, NS4B, NS5A and NS5B (Figure 1). ${ }^{3}$ NS proteins participate in different phases of the viral replication cycle (Figure 1). For example, NS3 to NS5B proteins are important for RNA replication. ${ }^{3}$ Jones et $a l^{41}$ showed that p7 and NS2 are required for entry and assembly of the virus. Other researchers have also reported that NS2, ${ }^{42-45} \mathrm{NS} 3 / 4 \mathrm{~A}^{46}$ and $\mathrm{NS} 5 \mathrm{~A}^{47,48}$ are involved in virion assembly and production.

Hepatocytes are the primary target cells for HCV replication. Upon infection, the virus particle circulating in the blood biochemically resembles the very low-density lipoprotein, which is rich in apolipoprotein (Apo) E and ApoB., ${ }^{3,49}$ First, the apolipoprotein-associated lipoviral particle (LVP) attaches to glycosaminoglycan and low-density lipoprotein receptor and then interacts with cluster of differentiation 81 (CD81) and scavenger receptor class $B$ number 1 (Figure 2). ${ }^{50}$ The LVP is subsequently translocated to the tight junction of hepatocytes where the LVP binds to the tight junction proteins claudin-1 and occludin followed by internalization of the HCV particle via $\mathrm{pH}$-dependent endocytosis, which occurs on the plasma membrane (Figure 2). ${ }^{50}$ In addition to these receptors, cell surface molecules, such as epidermal growth factor receptor, ephrin receptor A2 and Niemann-Pick C1-like L1 cholesterol uptake receptor, are also essential for virus internalization. ${ }^{50}$ Subsequent to internalization, the acidic $\mathrm{pH}$ in the endosome triggers fusion of the viral envelope with the endosomal membrane, allowing the release of the viral genome into the cytoplasm (Figure 2)..$^{50}$

$\mathrm{HCV}$ genomic translation occurs at the rough ER, and $\mathrm{HCV}$ RNA replicates in an ER-derived or ER-associated lipid-rich environment termed the membranous web (Figure 2). ${ }^{51}$ All HCV NS proteins except for NS2 are involved in viral RNA replication. The NS proteins are colocalized with the replicating viral RNA on a light density, detergent-resistant cytoplasmic membrane structure termed a 'lipid raft'. ${ }^{52}$ Lipid droplets (LDs), which comprise a neutral lipid core with a single phospholipid layer, serve as energy storage sites and reservoirs of neutral lipids in adipose tissue and hepatocytes. ${ }^{53}$ LDs are indispensable for viral RNA replication and infectious virus formation. ${ }^{54}$ During the initial stage of virus assembly, HCV core protein interacts with $\mathrm{LDs}^{55}$ and the viral replication complex is also directed to LDs in an NS5A- and core-dependent manner, allowing encapsidation of the viral RNA by the core protein and assembly of the nucleocapsid (Figure 2). ${ }^{47,54}$ Additionally, the interaction of NS3 and NS5A with actin and tubulin in the microtubule network mediates translocation of the HCV replication complex to LDs. ${ }^{56}$

The late stage of virus assembly, which occurs in the lumen of the ER, involves the acquisition of a lipid envelope, the embed- 


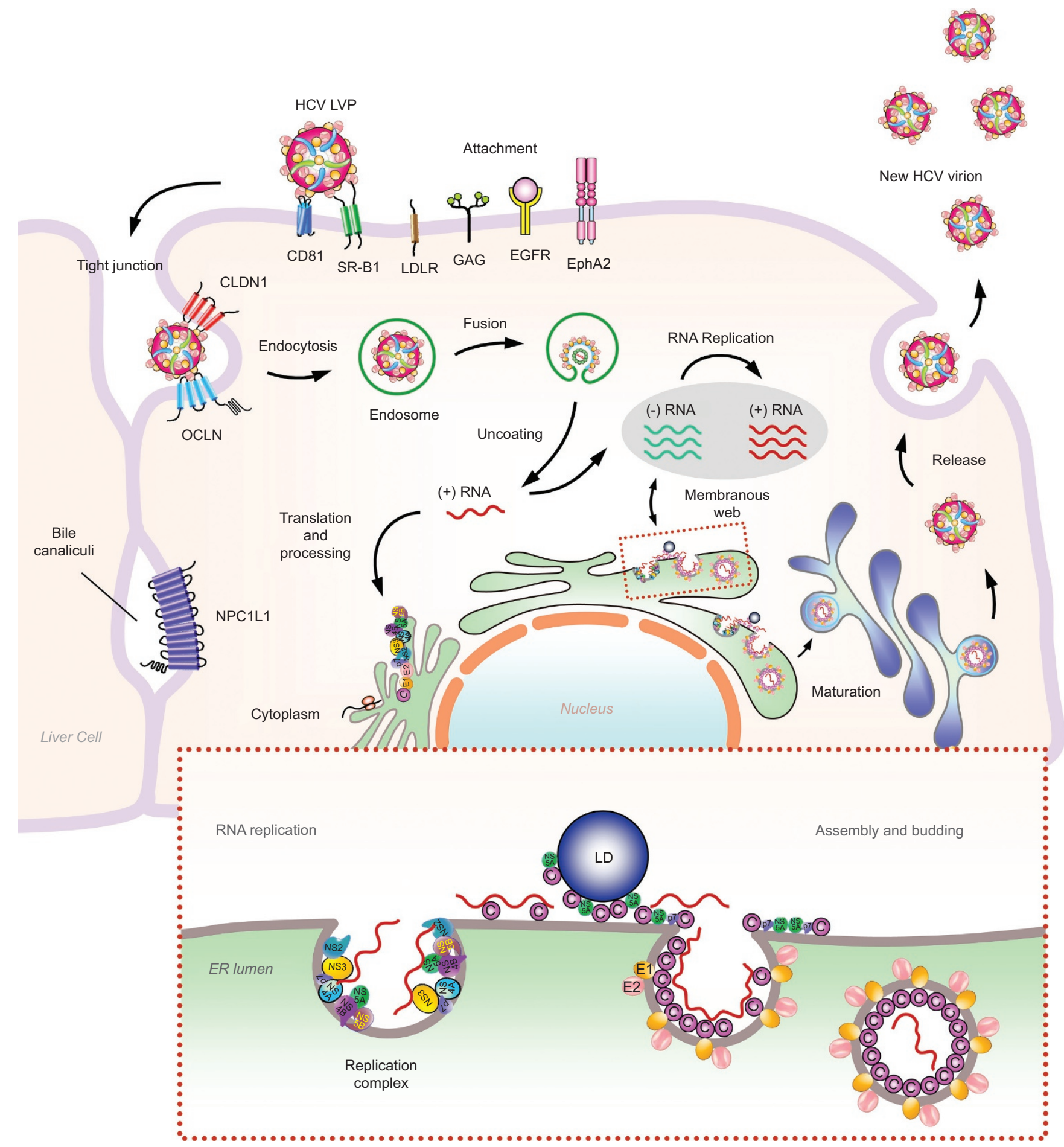

Figure 2 HCV replication cycle. As shown, the HCV LVP is coated with ApoB and ApoE, which are marked by light green and light blue stripes, respectively, on its surface. The LVP attaches to SRB1 and to CD81 and further interacts with the tight junction protein claudin-1 and with occludin. Virus entry into cell proceeds through receptor-mediated endocytosis at the cell surface. Subsequent to internalization, the viral envelope fuses with the endosomal membrane under acidic $\mathrm{pH}$, and the viral genome is uncoated and released into the cytoplasm. To dissect these two events, internalization and fusion are conventionally depicted as two seemingly separate steps in the cytoplasm. Viral RNA is translated at the ER to produce the polyprotein, which is subsequently processed into mature structural and non-structural proteins. Viral non-structural proteins, in conjunction with host factors, form a membranous web where viral RNA replication occurs. HCV particle assembly most likely initiates near the ER and LD where core protein and viral RNA accumulate. Finally, HCV particles are secreted into the extracellular milieu via the secretory pathway. Viral replication and assembly occur in the proximity of LDs and in lipid raft microdomains, which are shown in the inserted dashed rectangle. Apo, apolipoprotein; CD81, cluster of differentiation 81; ER, endoplasmic reticulum; HCV, hepatitis C virus; LD, lipid droplet; LVP, lipoviral particle. 
ding of E1 and E2 into the envelope and the formation of the nascent virion (Figure 2). Then, the nascent virus particles associate with ApoB, ApoE and other very low-density lipoprotein lipids to form LVPs. ${ }^{50}$ Finally, LVPs are released from cells through the very low-density lipoprotein secretion pathway or the endosome secretory pathway (Figure 2). ${ }^{50}$

Similar to the NS proteins, p7 plays numerous crucial functions in virion assembly and egress. ${ }^{57} \mathrm{p} 7$, an integral, oligomeric membrane protein consisting of 63 amino acids, is grouped into the family of viroporins that form membrane pores or channels. ${ }^{58}$ In functioning as an ion channel, p7 modulates membrane permeability to facilitate virus entry by promoting virus uncoating and to enhance assembly or release. ${ }^{58}$ p7 conducts ions across the membrane, and this channel activity can be abrogated by the drug amantadine and iminosugar derivatives. ${ }^{59,60}$ During maturation and egress, the ion channel activity of $\mathrm{p} 7$ maintains the $\mathrm{pH}$ gradients within the secretory pathway and thereby stabilizes the HCV particle. ${ }^{50}$ In addition, p7 has been shown to be necessary for capsid assembly and envelopment because mutations in $\mathrm{p} 7$ result in the accumulation of incompletely assembled capsids that are unable to encapsidate viral RNA. ${ }^{61}$

\section{VIRAL INFECTION AND INNATE IMMUNITY}

The IFN systems constitute the first-line defense mechanism against viral infection in humans. ${ }^{62}$ Based on their antiviral properties, IFNs are grouped into three classes: type I, II and III IFNs. ${ }^{63}$ In humans, type I IFNs comprise a large group of molecules encoded by multiple genes, mainly IFN- $\alpha$ and IFN- $\beta$, and other genes such as IFN- $\varepsilon$, IFN- $\kappa$ and IFN- $\omega .{ }^{64}$ IFN- $\alpha$ and IFN- $\beta$ combat viruses directly by inhibiting virus replication or indirectly by inducing the innate immune response. ${ }^{63}$ Most cell types can elicit a type I IFN response by activating the TLR, RLR and JAK-STAT pathways. ${ }^{64,65}$ Type II IFN contains only one member, IFN- $\gamma$. Unlike type I IFNs, which are elicited as a direct response to viral infection, IFN- $\gamma$ is secreted by natural killer cells and mitogenically activated T cells. ${ }^{63}$ IFN- $\gamma$ exerts potent anti-HCV activity in vitro and mediates antiviral T-cell responses. It has also been reported that IFN- $\gamma$ inhibits HCV infection by downregulating claudin- 1 and CD81. ${ }^{66}$ Type III IFNs consist of three members, termed IFN- $\lambda 1$, IFN- $\lambda 2$ and IFN- $\lambda 3$ or IL-29 $(\lambda 1)$ and IL-28A/B $(\lambda 2 / 3)$. As with type I IFNs, viral infection also directly activates type III IFNs. However, the antiviral properties and the mechanisms of action of type III IFNs remain unknown. Type III IFNs can be secreted by many cell types, but their receptors show a limited tissue distribution. ${ }^{63} \mathrm{HCV}$ infection results in type III IFN induction predominantly in the human liver. Despite modulation by the IRF3 and NF- $\mathrm{KB}$ pathways for induction of type III and type I IFNs, these two systems upregulate distinct subsets of ISGs with different kinetics of induction. ${ }^{67}$

During HCV infection, cells produce type I IFN to counteract viral infection, to modulate viral replication and to activate natural killer cells, dendritic cells and Kupffer cells. ${ }^{68}$ Recognition of PAMPs by PRRs, including TLRs and RLRs, triggers IFN synthesis and IFN-mediated cascade signaling pathways, leading to the production of type I IFN and a wide range of ISGs to mediate IFN antiviral activity (Figure 3). ${ }^{13,20-22}$

Upon virus infection, TLRs and RLRs operate through different signaling pathways, depending on the nature of the viral signals. TLRs are expressed and localized in the intracellular compartment, similar to endosomes, or on the cell surface. ${ }^{69,70}$ Unlike RLRs, TLRs potentially detect viral double-stranded RNA (dsRNA) released by cells into the extracellular milieu (Figure 3). ${ }^{69}$ Three types of TLRs, i.e., TLR3, TLR7 and TLR9, are involved in the recognition of virus infections. TLR3 detects the dsRNA formed during the replication of positive-stranded RNA viruses, whereas TLR7 recognizes the urine-rich ribonucleotide region of RNA, and TLR9 senses DNA PAMP motifs encoding CpG dinucleotides. ${ }^{69}$

Upon binding to a PAMP, TLR3 dimerizes and initiates the binding of its cytosolic Toll-IL-1 receptor to the adaptor protein Toll-IL-1 receptor domain-containing adaptor inducing IFN- $\beta$ (TRIF), resulting in the association of TLR3 with TRIF (Figure 3). ${ }^{13,14,19}$ This interaction leads to the recruitment of tumor necrosis factor (TNF) receptor-associated factor (TRAF) 6, TRAF3 and the TRAF family member nuclear factor kappa-light-chain-enhancer of activated B cells (NF- $\kappa \mathrm{B}$ ) activator-binding kinase 1 (TBK1), resulting in the phosphorylation and activation of IFN regulatory factor (IRF) 3 by TBK1 and by inhibitor of kappa B (IкB) kinase-related kinase (IKK)$\varepsilon{ }^{19,70}$ After phosphorylation, the IRF3 protein dimerizes and is translocated into the nucleus to form an enhanceosome complex with NF- $\kappa \mathrm{B}$ and other transcription factors, thereby inducing the expression of target genes, such as IFNs. ${ }^{70}$ Moreover, the binding of viral dsRNA to TLRs also activates NF- $\kappa B$ activity and pro-inflammatory cytokine synthesis through the interaction of TRIF with receptor-interacting protein-1. TLR7 and TLR9 bind to myeloid differentiation pro-inflammatory response 88 (MyD88) and activate IL-1 receptor-associated kinase (IRAK) and TRAF6, followed by the activation of IKK $\alpha / \beta$, which in turn activates NF- $\kappa B$ through phosphorylation, polyubiquitination and proteasomal degradation of its associated inhibitor I $\mathrm{K} \mathrm{\alpha}$. Migration of NF- $\kappa \mathrm{B}$ into the nucleus results in IFN production (Figure 3 ). ${ }^{70}$

The RLR receptors consist of RIG-I, melanoma differentiation-associated protein 5 (MDA5) and laboratory of genetics and physiology-2. ${ }^{13,16,18}$ RIG-I recognizes the HCV replication intermediate dsRNA within hours of infection, which triggers the downstream signaling before the viral protein is extensively synthesized (Figure 3). ${ }^{71}$ RIG-I senses the short, non-self dsRNAs with 5'-triphosphates, whereas RNAs lacking 5'PPP, such as picornaviruses, are recognized by MDA5. ${ }^{72}$ Both RIG-I and MDA5 contain two N-terminal caspase activator and recruitment domains (CARDs). ${ }^{24}$ The recognition of dsRNA by RIG-I is dependent upon the ATP-driven translocase activity of CARDs and helicases, and binding to dsRNA induces conformational changes in RIG-I that facilitate its oligomerization and translocation from the cytosol to the mitochondrial surface. ${ }^{73,74}$ On the mitochondria, RIG-I engages via its tandem CARDs with the CARD of its downstream effector, 


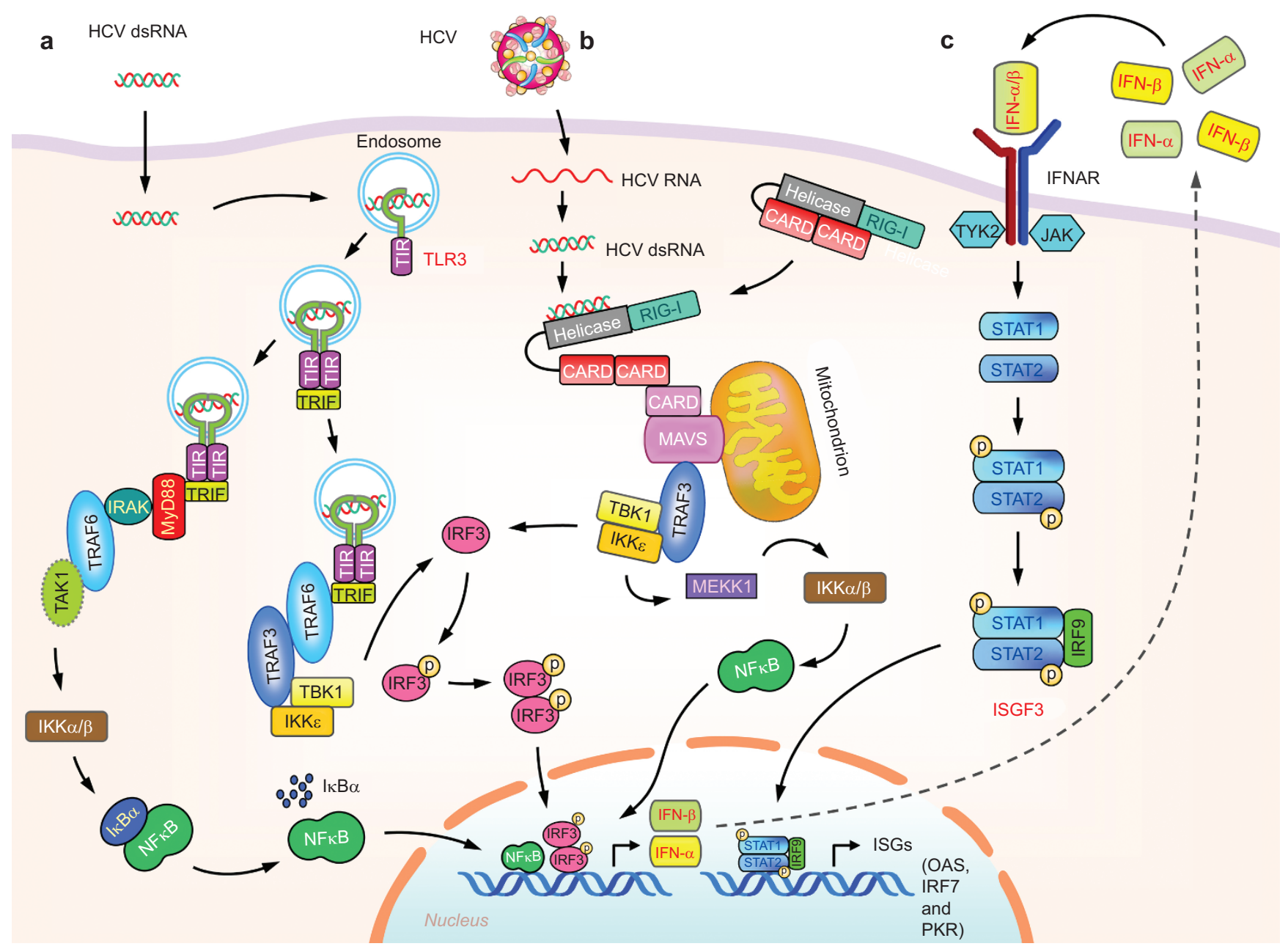

Figure 3 Induction of innate immunity by HCV in hepatocytes. Upon HCV infection, the viral dsRNA intermediate synthesized during viral replication is sensed by and activates the RIG-I and TLR 2 signaling pathways. (a) Upon binding to dsRNA, TLR interacts with its associated adapter protein TRIF and recruits TRAF, TBK1 and IKKe, thereby transmitting signals downstream to phosphorylate IRF3. Phosphorylated IRF3 dimerizes and translocates into the nucleus to induce the expression of target genes such as IFN. TLR also binds to MyD88 and activates IRAK, TRAF6 and IKK. These events activate NF-KB and IRF3, resulting in IFN production. (b) After sensing and binding to dsRNA, RIG-I interacts with MAVS. This interaction promotes the recruitment of TBK1 and IKKE and activates gene transcription through IRF3 phosphorylation and nuclear translocation. In addition, TRAF3, TRAF6 and MEKK1 are recruited to MAVS to activate NF- $\kappa B$. The canonical IKK $\alpha$ and IKK $\beta$ induce NF- $\kappa B-$ dependent gene transcription via phosphorylation, polyubiquitination and proteasomal degradation of $I \kappa B \alpha$, resulting in the release and nuclear

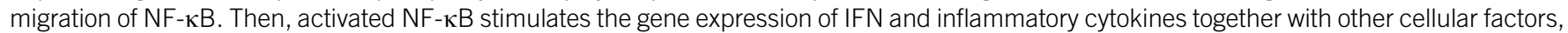
such as activating transcription protein 2 and c-Jun. (c) The secreted IFN binds to IFNAR on the plasma membrane and activates JAK-STAT signaling. Following IFN receptor binding, TYK2 and JAK activate and phosphorylate STAT1 and STAT2 to form a heterodimer, which subsequently recruits IRF9 to form the ISGF3 complex that translocates into the nucleus to activate the transcription of various ISGs. dsRNA, double-stranded RNA; HCV, hepatitis C virus; IFN, interferon; IFNAR, interferon- $\alpha / \beta$ receptor; IKK, I KB kinase-related kinase; IRF, IFN regulatory factor; ISG, IFNstimulated gene; JAK, Janus kinase; MAVS, mitochondria antiviral signaling protein; MEKK1, MAPK/ERK kinase 1; MyD88, myeloid differentiation pro-inflammatory response 88; NF-кB, nuclear factor kappa-light-chain-enhancer of activated B cells; RIG-I, retinoic acid-inducible gene 1; STAT, signal transducer and activator of transcription; TBK1, TANK-binding kinase 1; TLR, Toll-like receptor; TRAF, TNF receptor-associated factor.

mitochondria antiviral signaling protein (MAVS), which is also termed IFN- $\beta$ promoter stimulator-1, virus-induced signaling adaptor or CARD adaptor inducing IFN- $\beta$ (Figure 3 ). ${ }^{16,18}$ The chaperone protein $14-3-3 \varepsilon$ and the RING finger domaincontaining E3 ubiquitin ( $\mathrm{Ub})$ ligase triple motif-containing protein (TRIM) 25 also participate in this process. TRIM25 mediates the ubiquitination of RIG-I at position Lys-63, which is important for MAVS binding and for IFN production. ${ }^{74}$
The interaction between RIG-I and MAVS promotes the formation of a signaling complex on the mitochondrial surface that recruits and activates the downstream classical IKK complex, IKK $\alpha / \mathrm{IKK} \beta$, and two non-classical IKK-related kinases, TBK1 and IKKe. ${ }^{75,76}$ Activation of TBK1 and IKKe leads to the phosphorylation, dimerization and nuclear translocation of the transcription factor IRF3 (Figure 3). ${ }^{14}$ TRAF3, TRAF6 and mitogen-activator protein kinase/extracellular signal-regulated 
kinase (ERK) kinase 1 (MEKK1) are also recruited to MAVS to activate NF- $\kappa B .{ }^{24}$ The canonical IKK $\alpha$ and IKK $\beta$ induce NF$\kappa \mathrm{B}$-dependent gene transcription via phosphorylation, polyubiquitination and proteasomal degradation of $I \kappa B \alpha$, thereby resulting in the release and nuclear migration of NF- $\mathrm{KB}$. NF$\kappa \mathrm{B}$ activation involves the interaction of CARD9 with B-cell lymphoma/leukemia 10 protein. Activated NF- $\mathrm{KB}$ and IRF3 are translocated into the nucleus to form an enhanceosome, thereby stimulating the expression of IFN and inflammatory cytokines with the help of other cellular factors, such as activating transcription protein 2 and c-Jun. ${ }^{63}$

Then, secreted IFN binds to IFNAR on the cell surface and triggers the JAK-STAT signaling pathway (Figure 3). ${ }^{75,77}$ Following IFNAR receptor binding, tyrosine kinase- 2 and JAK1 are activated and phosphorylate STAT1 and STAT2 to form a heterodimer, which subsequently recruits IRF9 to form the transcription factor IFN-stimulated gene factor 3 (ISGF3). ${ }^{75}$ Then, ISGF3 is translocated into the nucleus, binds to IFNsensitive responsive element (ISRE) and transactivates the expression of various ISGs, such as $2^{\prime}-5^{\prime}$ oligoadenylatesynthetase (2-5OAS) $/ 2^{\prime}, 5^{\prime}$-linked oligoadenylate (2-5A)-dependent, latent endoribonuclease (RNase L), dsRNA-dependent protein kinase R (PKR), and IRF7 (Figure 3) ${ }^{78}$

\section{HCV EVASION OF ANTIVIRAL INNATE IMMUNITY}

Acute HCV infections can be spontaneously cleared in some infected individuals, suggesting that the innate immunity induced by HCV PAMP sensing can control acute viral infection. ${ }^{19,23}$ However, $80 \%$ of acutely infected people are not effectively cleared of HCV infection, and these patients may further develop chronic infection, suggesting that HCV has developed strategies to escape or to counteract the host immune response, leading to the emergence of resistance to IFN therapy. In this regard, several HCV proteins have been shown to block host antiviral responses, resulting in progression to chronic HCV infection (Figure 4). ${ }^{13,23,24}$ Obtaining further data regarding $\mathrm{HCV}$ evasion of host innate immunity will certainly improve IFN-based therapy outcomes.

\section{Core protein}

HCV core protein is involved in the formation of the viral nucleocapsid and modulates many cellular functions, including transcription and signal transduction. Expression of the full-length HCV genome or core protein downregulates IFN signaling by depressing STAT1 tyrosine phosphorylation, which then blocks STAT1 heterodimerization with STAT2 and inhibits IFN signal transduction and ISG expression (Figure 4). ${ }^{79}$ In addition, expression of core protein induces synthesis of suppressor of cytokine signaling 3 (SOCS3) in HepG2 cells. ${ }^{80}$ SOCS3 is an important repressor of the JAKSTAT pathway due to its ability to inhibit STAT1 phosphorylation (Figure 4) ${ }^{77,80}$ Thus, HCV core protein induces SOCS3 and suppresses IFN-mediated ISG expression. ${ }^{79-81}$ SOCS3 expression is upregulated in chronically HCV-infected patients who are IFN non-responders compared with responders. ${ }^{80}$ Core protein expression has also been demonstrated to inhibit
IRF1 synthesis, transcriptionally repressing several ISGs, such as IL-15, IL-12 and PKR. ${ }^{82}$

\section{E2}

Many viruses use molecular mimicry as an important immune evasion strategy to promote virus survival and persistence. ${ }^{83}$ Viruses express proteins that are structurally similar to host defense proteins, and these viral proteins can act as immune modulators. ${ }^{83} \mathrm{HCV}$ employs this molecular mimicry strategy to resist type I IFN through its E2 envelope protein. ${ }^{84,85}$ E2 comprises a 12 -amino acid sequence identical to eukaryotic initiation factor $2 \alpha$ (eIF2 $\alpha$ ) and PKR. ${ }^{84}$ This domain operates to prevent PKR-dependent phosphorylation of eIF $2 \alpha$ and repression of protein synthesis, thus possessing an ability to resist type I IFN treatment (Figure 4$) .8{ }^{84,85}$

\section{NS3/4A}

The HCV NS3/4A protease is not only responsible for the maturation of NS proteins, viral RNA replication and virion morphogenesis but is also important for suppressing the host antiviral system. ${ }^{13,19,23,24,86}$ The NS3/4A complex is anchored to the intracellular membrane through the NS4A transmembrane domain and the amphipathic $\alpha$-helix at the NS3 N-terminus. ${ }^{87}$ All these domains facilitate cleavage of their two cellular targets, MAVS and TRIF, which act as key players in type I IFN production (Figure 4). ${ }^{88,89}$

MAVS is an essential antiviral signaling protein in the RLR system and, therefore, is an ideal target for viral immune evasion. NS4A serves as the primary membrane subcellular targeting subunit to escort NS3/4A to MAVS. ${ }^{86}$ NS3/4A binds to MAVS on mitochondria ${ }^{88}$ and cleaves MAVS at Cys-508, resulting in the dislocation of the $\mathrm{N}$-terminal portion of MAVS from mitochondria and the suppression of IFN production (Figure 4$).^{71}$ The hydrophobic amino acid stretch in the NS3 amphipathic $\alpha$-helix is also required for controlling RIG-I signaling. ${ }^{86}$ Cleavage of MAVS and reduction of IFN levels have been observed in chronically HCV-infected patients. ${ }^{90}$ Thus, NS3/4A-mediated cleavage of MAVS RIG-I signaling impairs IFN synthesis. ${ }^{90}$

Additionally, the NS3/4A protease also cleaves TRIF, an adaptor protein linking TLR3 to kinases responsible for activating IRF3 and NF- $\kappa B$ (Figure 4). ${ }^{89,91}$ Cleavage of TRIF interferes with poly(I:C)-activated TLR signaling and IRF3 and $\mathrm{NF}-\kappa \mathrm{B}$ activation, thereby limiting the expression of multiple host defense genes and enhancing HCV persistence. ${ }^{89}$

\section{NS4B}

Stimulator of interferon gene (STING), which is also known as mediator of IRF3 activation (MITA), is a $42-\mathrm{kDa}$ protein mainly localized to the ER. ${ }^{92}$ In response to dsDNA transfection or DNA virus infection, STING plays a crucial role in the activation of transcription pathways, essential for effective innate immune signaling. ${ }^{92}$ Upon dsDNA stimulation, STING polymerizes and translocates from the ER to a cytoplasmic punctate structure where the STING polymer provides a platform to 


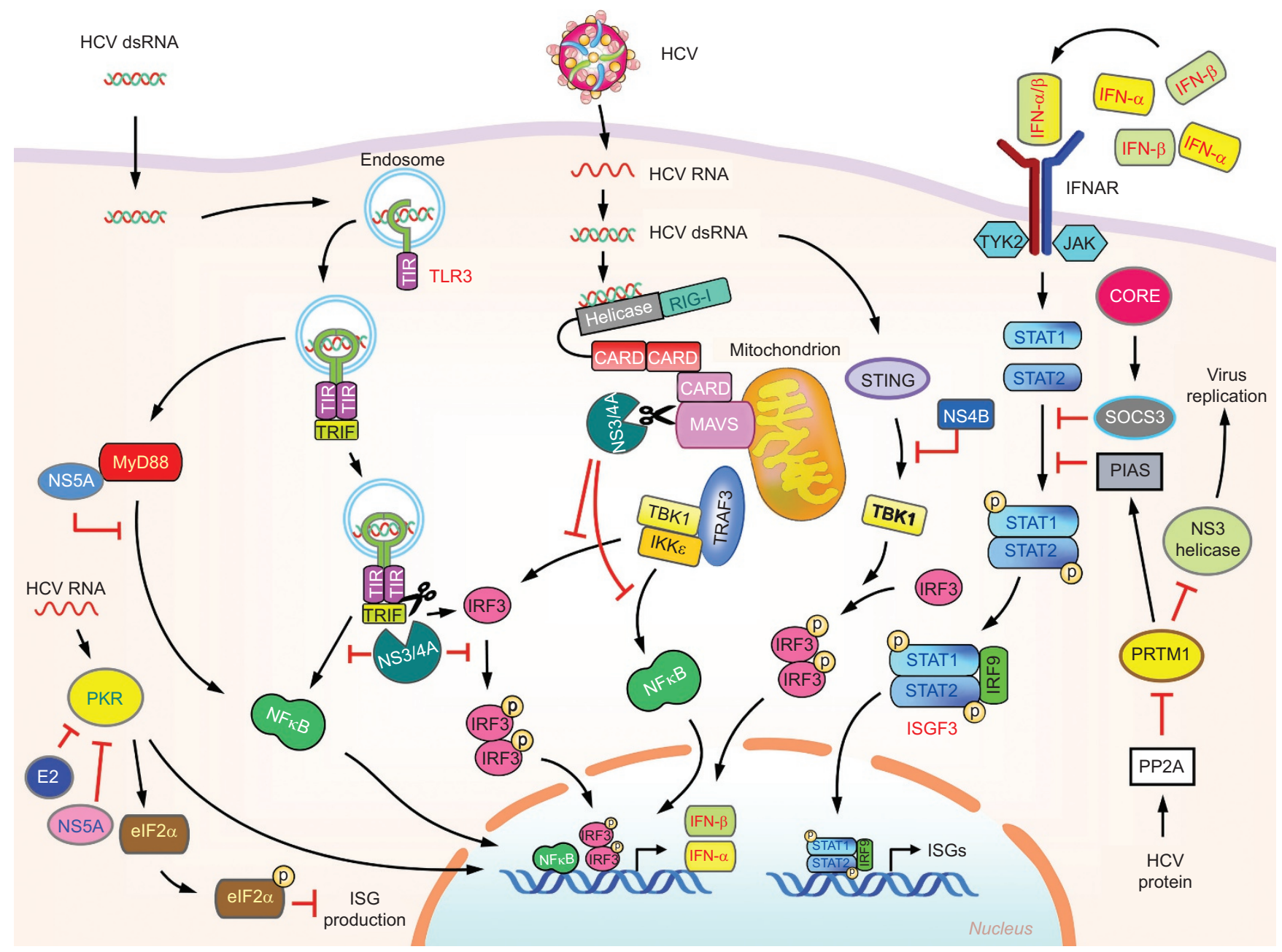

Figure 4 Evasion of innate immunity by HCV viral proteins. HCV NS3/4A protease cleaves the TRIF and MAVS adapters, thereby crippling innate immune antigen recognition and type I IFN induction signaling. NS5A interacts with MyD88 to inhibit TLR signaling. NS5A inhibits PKR activation via its ISDR, resulting in IFN resistance. The HCV IRES can bind to the dsRNA-binding domain of PKR and can increase PKR autophosphorylation and activation, thereby enhancing viral protein translation. Furthermore, HCV-mediated phosphorylation and activation of PKR inhibits its downstream target elF2 $\alpha$ and attenuates the expression of ISGs, promoting viral replication. The E2 protein antagonizes the PKR-dependent activation of host elF2 $\alpha$, resuming translation. NS4B interacts with STING/MITA to inhibit downstream IRF3 signaling. Moreover, core induces the expression of SOCS3 and attenuates the STAT1 phosphorylation pathway. Expression of HCV induces the expression of PP2A, which inhibits PRMT1 enzymatic activity. Inhibition of PRMT1 activity decreases methylation of STAT1, which favors binding to PIAS1, resulting in the disruption of STAT1 signaling, impairment of ISG production, and HCV evasion of innate immunity. Additionally, decreased PRMT1 activity enhances NS3 helicase activity, which in turn promotes virus replication. elF2 $\alpha$, eukaryotic initiation factor $2 \alpha$; HCV, hepatitis C virus; IFN, interferon; IRF, IFN regulatory factor; ISG, IFNstimulated gene; MAVS, mitochondria antiviral signaling protein; MITA, mediator of IRF3 activation; MyD88, myeloid differentiation pro-inflammatory response 88; NS, non-structural protein; PIAS1, protein inhibitor of activated STAT1; PKR, dsRNA-dependent protein kinase R; PRMT1, protein arginine methyltransferase 1; SOCS3, suppressor of cytokine signaling 3; STAT, signal transducer and activator of transcription; STING, stimulator of interferon gene; TLR, Toll-like receptor; TRIF, TIR domain-containing adaptor inducing IFN- $\beta$.

connect TBK1 with IRF3, which phosphorylates IRF3, thereby triggering downstream signaling. ${ }^{93}$

In viral infection, NS4B from yellow fever virus (YFV) blocks the induction of the IFN production pathway through an interaction with STING. ${ }^{94}$ NS2B3 from dengue virus (DenV) acts as a protease to cleave STING, thereby shutting down IFN signaling. ${ }^{95}$ In HCV infection, NS4B interacts with and sequesters STING on the ER to inhibit the association of STING with TBK, suppressing IFN signaling (Figure 4) ${ }^{96,97}$ Therefore, targeting STING to inhibit innate immunity might be beneficial for virus survival.

\section{NS5A}

The mature HCV NS5A is present as two phosphoproteins, the hypophosphorylated p56 and hyperphosphorylated p58. ${ }^{98,99}$ NS5A phosphorylation occurs at multiple serine residues, such as serine 225, 229 and 232 upstream of the IFN sensitivity determining region (ISDR) of NS5A, which spans residues 237-276 (based on genotype 1b HCV-J strain), and these serine residues are important for hyperphosphorylation. ${ }^{98,100}$ The functional and locational significance of NS5A p56 and p58 remains unclear; however, maintenance of these two forms at a specific ratio is critical for HCV replication. ${ }^{100,101}$ NS5A 
functions as a pleiotropic protein that modulates the host environment to favor virus replication and persistence. ${ }^{102}$ Additionally, NS5A binds to MyD88, which is a major adaptor molecule in the TLR pathway, and inhibits the recruitment of IRAK1 to MyD88, attenuating TLR signaling and impairing cytokine production. ${ }^{103}$ A sequence within the NS5A ISDR, which spans residues 237-302, was shown to be responsible for interaction with the death domain of MyD88 in macrophage cells. ${ }^{103}$

PKR is an IFN-induced gene product that is activated by binding to dsRNAs commonly produced during viral replication. NS5A rescues HCV replication in IFN-treated cells and inhibits IFN antiviral activity by binding to PKR and blocking PKR autophosphorylation and eIF2 $\alpha$ phosphorylation. ${ }^{23,104}$ NS5A expression is sufficient to rescue the replication of an IFN-sensitive virus. ${ }^{102}$ The interaction of PKR with NS5A requires the ISDR that overlaps a broader PKR-binding region, residues 234-366, and results in the inhibition of PKR activation and resistance to IFN in HCV-expressing cells. ${ }^{104,105}$ Consistent with this mechanism, mutations in or deletion of ISDR correlate with sensitivity to IFN- $\alpha$-mediated antiviral activity. ${ }^{102,105,106}$ Moreover, meta-analysis and long-term follow-up support the association of this ISDR region with the outcome of IFN therapy. This region, which encompasses a genetically flexible domain that allows mutations to occur, is the key site of adaptation to IFN therapy and influences the fitness of HCV RNA replication. ${ }^{23}$

In contrast, other studies suggest that the inhibitory effect of NS5A on IFN may be independent of PKR. NS5A increases expression of IL-8, also known as chemokine CXCL8, by upregulating the IL-8 promoter, which in turn, inhibits IFN antiviral activity and facilitates virus infection. ${ }^{107,108}$ In a cell culture model, IL-8-positive cells are associated with chronic HCV infection, and IL-8 removal mitigates HCV replication. ${ }^{108}$ Importantly, the serum level of IL-8 is elevated in chronic hepatitis $\mathrm{C}$ patients compared with control individuals or is higher in IFN non-responders relative to responders. ${ }^{23}$ These observations suggest that NS5A expression increases IL-8 production, which somehow perturbs the IFN antiviral pathway.

Moreover, NS5A impedes the 2-5OAS/RNase L system to inhibit IFN signaling. ${ }^{109}$ The 2-5OAS/RNase L antiviral pathway is present in virtually every cell. ${ }^{110}$ This pathway involves the activation of a latent endoribonuclease and degrades HCV mRNA with a dsRNA structure during replication. ${ }^{110}$ NS5A physically binds to 2-5OAS through amino acid residues 1 40 of NS5A. ${ }^{109}$ A single point mutation at amino acid 37 of NS5A affects the NS5A and 2-5OAS binding and the antiviral activity of the 2-5OAS/RNase L system. ${ }^{109}$ Thus, NS5A inhibits IFN antiviral activity in an ISDR-independent manner. Moreover, IFN-resistant strains, such as genotypes $1 \mathrm{a}$ and $1 \mathrm{~b}$, have fewer RNase $\mathrm{L}$ recognition sites in their genomes than the IFN-sensitive strains, such as genotypes 2 and 3 , providing a means for IFN-resistant strains to escape from nucleotylic cleavage. ${ }^{110}$
Apoptosis also plays a key role in the host defense system by restricting viral spread and persistence. Blocking apoptosis could be critical for the establishment of life-long persistence in the host organism. NS5A was shown to block the activation of caspase 3 and to inhibit proteolytic cleavage of the death substrate poly(ADP-ribose) polymerase in TNF- $\alpha$-induced cells. ${ }^{111}$ Adenovirus infection in NS5A-transgenic mice downregulates and upregulates the expression of T-box transcription factor 21 and trans-acting T cell-specific transcription factor 3 , respectively, resulting in lower IFN- $\gamma$ expression and a delay in virus clearance. ${ }^{112}$ Furthermore, stable expression of NS5A in the human hepatoma cell line Huh7 decreases sensitivity to TNF- $\alpha$-mediated apoptosis, and activation of caspase- 3,8 and 9 by TNF- $\alpha$ is inhibited in NS5A-expressing cells. ${ }^{113}$ Thus, NS5A protects cells from TNF- $\alpha$-mediated apoptotic death.

\section{HCV-induced ER stress}

HCV protein expression can induce an ER stress response and lead to calcium release from the ER, which in turn activates the cyclic AMP responsive element-binding protein that binds to the cyclic AMP responsive element in the promoter of protein phosphatase 2A (PP2A), resulting in upregulation of PP2A. ${ }^{114}$ Expressed in essentially all cell types, $\mathrm{PP} 2 \mathrm{~A}$ is a serine/threonine phosphatase that is involved in multiple cellular processes, such as the cell cycle, signal transduction and stress response. ${ }^{115,116}$ Increased expression of PP2A has been observed in a cell line inducibly overexpressing HCV protein, in liver extracts from HCV transgenic mice and in liver biopsies from patients with chronic hepatitis C. ${ }^{117}$

Duong et al. ${ }^{117}$ showed that upregulation of PP2A by HCV can inhibit the enzymatic activity of protein arginine methyltransferase 1 (PRMT1), which leads to decreased methylation of STAT1. Hypomethylated STAT1 is more prone to bind to protein inhibitor of activated STAT1 and inhibits STAT1 dimerization, resulting in impaired nuclear translocation into the nucleus, binding of STAT1 to the ISRE, and ISG production. ${ }^{117}$ Thus, HCV-induced PP2A activation disrupts the IFN$\alpha$-induced antiviral state, leading to HCV evasion of innate immunity. These authors also showed that PRMT1 can methylate HCV NS3 at arginine 467, resulting in the inhibition of NS3 helicase activity. ${ }^{118}$ Therefore, HCV-mediated PP2A upregulation enhances NS3 helicase activity by inhibiting PRMT1 enzymatic activity, which in turn facilitates virus replication. ${ }^{118}$

\section{FUNCTIONS OF ISGS IN INNATE ANTIVIRAL RESPONSES AND HCV REPLICATION}

Human genomes encode hundreds of ISGs, ${ }^{23}$ and the first ISG, $54 \mathrm{~K}$, was discovered more than 25 years ago. ${ }^{119}$ Synthesis of some ISGs can be triggered by viral infection without IFN production. Some ISG products can directly regulate cellular processes, such as protein synthesis and cell growth, survival and apoptosis, whereas others may modify the IFN antiviral activity against invading viruses. ${ }^{120}$ The gene products of ISGs can target many steps in the HCV replication cycle to limit viral replication. ${ }^{23}$ Many PAMP receptors and their subsequent sig- 
naling partners are also ISGs. ${ }^{23}$ ISGs expressed at the basal level provide antiviral surveillance before IFN activation or therapy; however, their levels markedly increase after IFN production. ${ }^{23}$

In the innate immune response to virus infection, viral RNA acts not only as a inducer of the production of IFN and its effector functions but also as a substrate and product for cellular enzymes, such as PKR and 2-5OAS/RNase L. ${ }^{121}$ The inverse correlation between the upregulated expression of ISGs, such as OAS-like (OASL), ISG15 and viperin, in liver biopsies from $\mathrm{HCV}$-infected patients and infected hepatocytes and decreased viral RNA levels suggest the anti-HCV activities of these ISGs. ${ }^{122}$ In this section, we will highlight the involvement of ISGs that are critical for modulating innate immunity in HCV replication, and the potential functions of these ISGs, as outlined in Table 1.

\section{RIG-I}

RIG-I, which is encoded by the DDX58 gene and which belongs to the DExD/H box RNA helicase (DDX) family, is a key player in the defense against invasion by many RNA viruses. ${ }^{72}$ RIG-I senses the intracellular viral components and initiates antiviral responses to stimulate IFN production (Table 1). In turn, IFN activates the transcription of RIG-I, hence forming a positive feedback loop for amplifying antiviral signals. ${ }^{123}$ Studies have shown that RIG-I is essential for eliciting an immune response against vesicular stomatitis virus (VSV), Sendai virus, Newcastle disease virus (NDV) and hepatitis C virus. ${ }^{72,124,125}$ Knockout of the RIG-I gene in mouse embryonic fibroblasts severely limits type I IFN production and ISG activation, thereby potentiating viral replication; conversely, overexpression of RIG-I restricts viral replication. ${ }^{72}$ In addition, upregulation of RIG-I gene

Table 1 Functions of ISGs in HCV replication

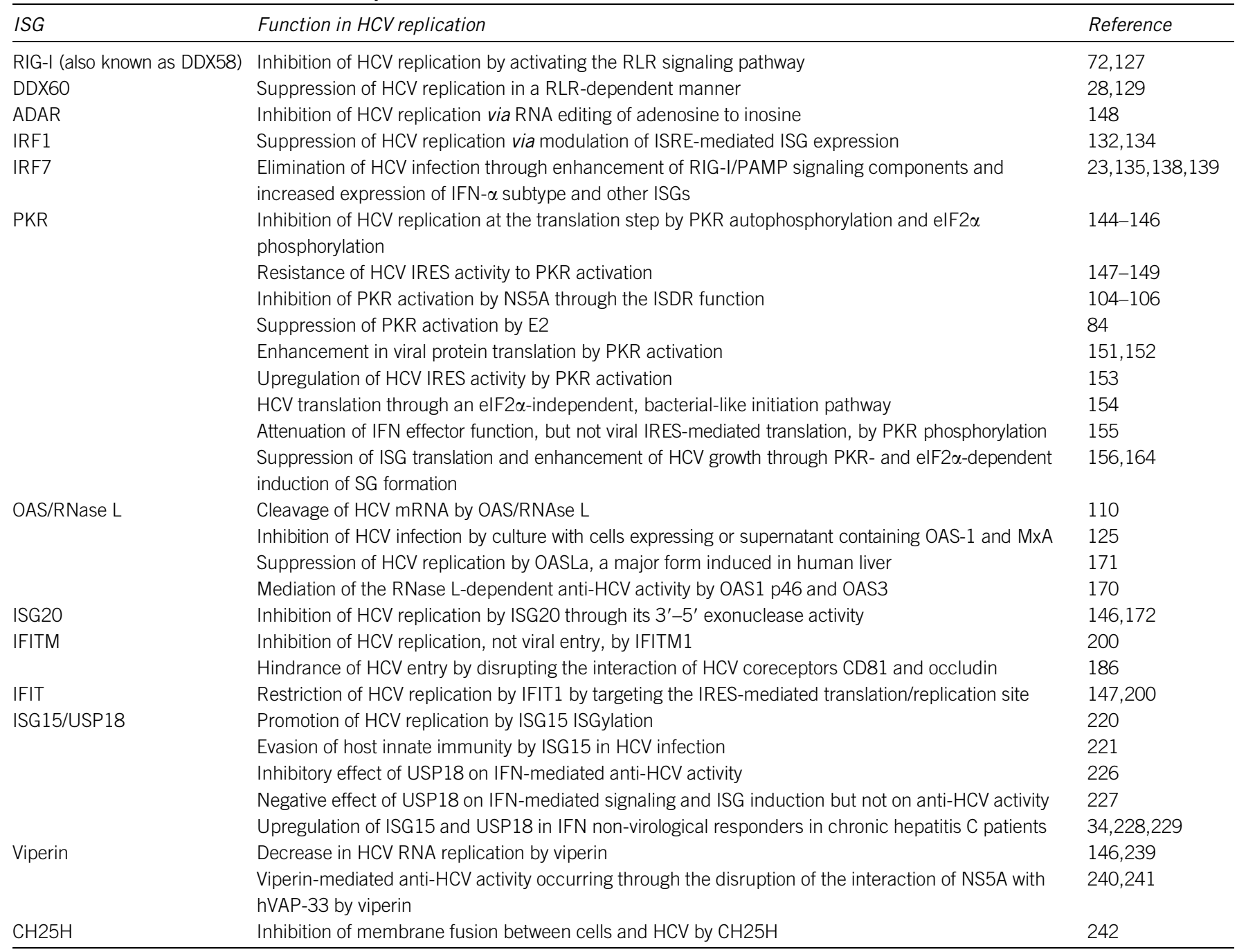

Abbreviations: ADAR, RNA-specific adenosine deaminase; $\mathrm{CH} 25 \mathrm{H}$, cholesterol-25-hydroxylase; DDX, DExD/H box RNA helicase; elF2 $\alpha$, eukaryotic initiation factor $2 \alpha$; HCV, hepatitis $\mathrm{C}$ virus; IFITM, IFN-inducible transmembrane protein; IFN, interferon; IRF, IFN regulatory factor; ISDR, interferon sensitivity determining region; ISG, IFN-stimulated gene; ISRE, IFN-sensitive responsive element; mRNA, microRNA; MxA, myxovirus resistance gene A; NS, non-structural protein; PAMP, pathogen-associated molecular pattern; PKR, dsRNA-dependent protein kinase R; RIG-I, retinoic acid-inducible gene 1; RLR, RIG-I-like receptor; RNase L, 2-5A-dependent endoribonuclease latent form; USP18, UBL-specific protease 18; VAP, vesicle-associated membrane protein. 
expression has been observed in IFN-treated human dendritic cells, suggesting that RIG-I serves as an ISG. ${ }^{126}$

RIG-I contains two tandem CARDs at its $\mathrm{N}$-terminal region, with a repressor domain in its $\mathrm{C}$-terminal region. The CARD is responsible for downstream signaling and activation of type I IFN after recognition of non-self RNA, whereas the repressor domain is essential for the autoregulation and recognition of viral RNAs. ${ }^{127}$ Without viral stimulation, the CARD interacts with the helicase domain, placing RIG-I in an auto-inhibitory state and disabling signal transduction. ${ }^{127}$

Upon binding to viral RNA, RIG-I undergoes conformational changes that expose the CARD, allowing RIG-I to be ubiquitinated. ${ }^{127}$ RIG-I is ubiquitinated by two different ligases, TRIM25 and Ring finger protein 125 . TRIM25 ubiquitinates RIG-I at lysine 172 to mediate the antiviral response, whereas ubiquitination by Ring finger protein 125 regulates the degradation of RIG-I by the proteosome, thereby downregulating RIG-I-mediated signaling. ${ }^{123}$ Ubiquitination by TRIM25 induces RIG-I to form a tetramer, promoting the CARDs of RIG-I to engage with the CARDs of MAVS. This results in the accumulation of MAVS on the mitochondrial membrane and the activation of IKK and TBK1, which, in turn, activates the transcription of NF- $\mathrm{KB}$, IRF3 and IRF7 to promote IFN production. ${ }^{123}$ Moreover, ubiquitination by TRIM25 also prevents CARDs from interacting with the helicase domain to reinstate the auto-inhibitory state. ${ }^{127}$ Ubiquitination at lysine 172 is crucial for RIG-I function because a mutation at this residue renders RIG-I unable to bind to MAVS, thus abrogating downstream signaling. ${ }^{128}$

\section{DDX60}

DDX60 is also a $\mathrm{DExD} / \mathrm{H}$ box helicase whose function remains unclear. ${ }^{129}$ DDX60 slightly resembles the yeast Ski protein, which is a cofactor of the RNA exosome required for controlling host RNA quality. ${ }^{129}$ DDX60, which is the human homolog of yeast Ski, and the RNA exosome exhibit antiviral activity against monkey leukemia virus and Sindbis virus (SINV). ${ }^{129}$ DDX60 expression is upregulated during infections of measles virus $(\mathrm{MeV})$ and HCV. ${ }^{28,129}$ The DDX60 mRNA level is robustly upregulated in human fetal liver cells within $24-48 \mathrm{~h}$ after HCV infection, providing a means to initiate the antiviral mechanism. ${ }^{130}$

Unlike RIG-I, DDX60 does not contain the CARDs to interact with MAVS. ${ }^{129}$ After viral infection, DDX60 is induced and binds to RIG-I as well as MDA5 and laboratory of genetics and physiology-2 and promotes the binding of RIG-I to dsRNA. ${ }^{28,129}$ DDX60 is essential for type I IFN expression during DNA virus infection and is induced to suppress viral replication in a RLR-dependent manner (Table 1). ${ }^{129}$ DDX60 knockdown reduces the expression of type I IFN after HCV, HIV and YFV infections. ${ }^{28}$

\section{IRF1}

IRF1 was first identified as a transcriptional activator of the IFN- $\alpha / \beta$ gene. In unstimulated cells, IRF1 is expressed at a low level; however, its expression is increased by the induction of
IFN- $\alpha / \beta$, TNF- $\alpha$, IL- 1 and viral infection. ${ }^{131}$ Nevertheless, the precise pathway leading to IRF1 activation by virus infection remains elusive. IRF1 activation may proceed through a PKRdependent pathway after virus infection. PKR indirectly phosphorylates IRF1 and activates its DNA-binding properties. Thus, activated IRF1 regulates the promoter function of IFN $\alpha / \beta$ promoter and acts as a modulator of many ISGs by binding to the ISRE in the promoter region, thereby regulating viral replication (Table 1). ${ }^{82,132}$

IRF1 controls the IFN antiviral response by affecting a set of ISGs, such as IRF7 and IRF3. ${ }^{131}$ IRF1 cooperates with IRF3 and IRF7 to regulate cellular antiviral genes, such as IFN- $\alpha / \beta$. HCV infection increases the level of IRF1, which may affect other IRF pathways and ISG expression, thereby leading to a reduction in viral replication. ${ }^{132}$ IRF1 overexpression induces an antiviral state that affects various viruses, including NDV, VSV and HCV. ${ }^{133,134}$ The expression level of IRF1 is reduced in cells harboring HCV subgenomic replicons (SGRs), whereas IRF1 overexpression in these cells increases the ISRE activity and attenuates HCV replication. ${ }^{134}$ Additionally, HCV infection mediates IRF1 expression, thus affecting the intracellular level of HCV RNA. ${ }^{134}$ However, HCV may evade the IRF1 anti-HCV effect through core-mediated suppression of IRF1 synthesis. ${ }^{82}$

\section{IRF7}

IRF7 is an essential transcription factor for the induction of IFN- $\alpha / \beta$ and ISGs. All of the elements of IFN responses, either innate or adaptive immunity, are regulated by IRF7. ${ }^{135}$ IRF7 is constitutively expressed in certain cells, such as macrophage and plasmacytoid dendritic cells, priming these cells for rapid IFN production. ${ }^{23}$ During infection, IFN- $\alpha / \beta$ binds to its receptor and activates the JAK-STAT pathway, resulting in IRF7 expression. ${ }^{23}$ Then, IRF7 is phosphorylated, forms a heterodimer with IRF3 and is translocated into the nucleus. ${ }^{136}$ In the nucleus, the IRF7-IRF3 heterodimer binds to the IRF elements in the promoter region of IFN- $\alpha$ genes, leading to enhanced expression of the IFN- $\alpha$ subtype and a diverse range of ISGs (Table 1). ${ }^{23,135}$ In turn, these events increase the abundance of RIG-I and viral PAMP signaling components, whereas sustained signaling serves to amplify IFN production. ${ }^{23,135}$ Moreover, IRF7 induces expression of other ISGs without activating IFN signaling. ${ }^{137}$ Thus, IRF7-mediated transcriptional cascades serve as an intrinsic antiviral mechanism allowing rapid ISG expression before IFN production.

IRF7 plays an important role in eliminating HCV infection. siRNA knockdown of IRF7 decreases IFN- $\alpha$ production and increases the HCV titer. ${ }^{138,139}$ Mice lacking IRF7 show rapidly lethal infection by West Nile virus (WNV) and high virus burdens. ${ }^{140}$ IRF7 deficiency represses the induction and accumulation of IFN- $\alpha$, thus favoring WNV replication. ${ }^{140}$ Although HCV seems to suppress the basal expression of IRF7, TLR7 stimulation activates IRF7 and suppresses HCV replication. ${ }^{138}$ This observation suggests that HCV may only partially inhibit IRF7 activity in HCV-expressing cells. ${ }^{138}$ 


\section{PKR}

$\mathrm{PKR}$, which is also known as EIF2 $\alpha \mathrm{K} 2$, is a serine/threonine kinase that phosphorylates eIF2 $\alpha$ in response to virus infection. This IFN-inducible kinase has two distinct activities: autophosphorylation, resulting in its activation, and phosphorylation and inactivation of eIF $2 \alpha$. Through phosphorylation events, PKR mediates the inhibition of translation initiation of both cellular and viral mRNA. ${ }^{141-143}$ It is well documented that the anti-HCV activity of PKR occurs through its translational control (Table 1). ${ }^{144-146}$ However, viruses have evolved elaborate strategies to counteract the detrimental effects of PKR. HCV IRES activity has been shown to be resistant to PKR activation in cells harboring HCV SGR and in the HCV infection model (Table 1). ${ }^{147-149}$

Mechanistically, viruses may use their proteins to impede the dsRNA-dependent pathway in various ways, such as sequestering dsRNA, inhibiting PKR activation, producing PKR pseudosubstrates, activating antagonist phosphatases and degrading PKR. ${ }^{142}$ As indicated above, HCV employs NS5A and E2 to antagonize PKR function, resulting in resistance to IFN and a blockade of the PKR-mediated inhibition of viral protein synthesis (Table 1).

Analogous to alphaviruses SINV and Semliki Forest virus, ${ }^{150}$ HCV can activate PKR and eIF2 $\alpha$ phosphorylation to enhance its own viral protein translation (Table 1). ${ }^{151,152}$ Compared with other previously studied dsRNAs, domains III-IV of the HCV IRES were shown to bind to the N-terminal dsRNAbinding domain of PKR, leading to increased PKR autophosphorylation and activation. ${ }^{152}$ Additionally, cap-dependent but not HCV IRES-mediated translation is inhibited by PKR and eIF $2 \alpha$ phosphorylation. ${ }^{152}$ These results indicate that while escaping the deleterious effects of PKR activation, HCV can employ its structured IRES to direct its own protein translation. Karamichali et al. ${ }^{153}$ demonstrated that activated PKR or silencing PKR upregulates or downregulates HCV IRES activity (Table 1). These authors further showed that the inhibitory effect of NS5A on IRES-dependent translation occurs through PKR inactivation. ${ }^{153}$ In contrast, HCV can translate its viral protein via a bacterial-like pathway that uses eIF5B, which is an analog of bacterial IF2, and eIF3, instead of eIF $2 \alpha$ and its GTPase-activating protein eIF5, as the initiation factor (Table 1). ${ }^{154}$ The use of eIF $2 \alpha$-independent translation initiation provides an alternative tactic for $\mathrm{HCV}$ translation when eIF $2 \alpha$ is inactivated by phosphorylation under stress conditions.

Many lines of evidence have revealed that HCV-mediated phosphorylation and activation of PKR, in turn, inhibit its downstream target, eIF2 $\alpha$, and attenuate the expression of host cellular proteins, including ISGs, without any inhibitory effects on viral IRES-mediated viral protein translation (Table 1). ${ }^{143,155,156}$ PKR knockdown in HCV-infected cells restores ISG expression and enhances the antiviral effect of IFN. ${ }^{155}$ These results demonstrate that HCV escapes IFN antiviral activity by promoting the phosphorylation of PKR and inhibiting the production of antiviral ISG proteins, thus providing an interesting pathway for the virus to evade the IFN antiviral response.

Furthermore, accumulating evidence has revealed that PKR and eIF $2 \alpha$ participate in the formation of stress granules (SGs). SGs are large, dynamic structures between 50 to $200 \mathrm{~nm}$ in size, that form in the cytoplasm when cells undergo extracellular stresses, including viral infections. ${ }^{157}$ SG formation is important for the posttranscriptional regulation of gene expression. ${ }^{157}$ SGs contain stalled translation pre-initiation complexes, including cellular mRNAs, translational initiation factors, the small subunit of the ribosome and many cellular RNA binding proteins, such as T-cell-restricted intracellular antigen 1 (TIA-1), the homologous TIA-1-related protein TIAR and RasGAP-SH3 domain binding protein 1 (G3BP1), involved in regulating mRNA functions. ${ }^{158-161}$

Many viruses, including HCV, can modulate SG assembly and co-opt SGs to promote their own protein synthesis. ${ }^{162,163}$ HCV induces SG formation via eIF2 $\alpha$ phosphorylation (Table 1). ${ }^{156,164}$ Consistent with this notion, upregulation of the regulatory subunit of protein phosphatase 1 that dephosphorylates eIF2 $\alpha$ and growth arrest DNA damage-inducible protein 34, inhibits SG formation. ${ }^{164}$ These results indicate the importance of eIF $2 \alpha$ phosphorylation in $\mathrm{HCV}$-induced SG formation.

Moreover, Garaigorta et al. ${ }^{156}$ demonstrated that HCVinduced SG formation is IFN- and PKR-dependent and is inversely correlated with the induction of ISG proteins, such as myxovirus resistance gene $A(\mathrm{MxA})$ and Ub-like (UBL)specific protease 18 (USP18), in HCV-infected cells without affecting the mRNA levels of these ISGs. Furthermore, the SG proteins TIA-1, TIAR and G3BP1 have been shown to play a critical role in HCV replication and infectious virus production. ${ }^{156}$ In support of this finding, G3BP1 was also reported to be essential for HCV RNA replication, presumably through its relocalization to LDs or its interaction with NS5B. ${ }^{165,166}$ The results of Garaigorta et al. ${ }^{156}$ demonstrated that HCV hijacks PKR phosphorylation-triggered SG formation to downregulate the translation of antiviral ISGs, thereby promoting viral RNA replication, virus assembly and egression.

\section{OAS and RNase L}

Upon sensing and activation by the PAMP of viral dsRNA, certain IFN-stimulated 2-5OAS proteins can synthesize 2-5A from ATP. After binding to 2-5A short oligoadenylates, a ubiquitous, latent endonuclease, RNase L, is activated through dimerization and degrades either cellular or viral RNAs, resulting in the inhibition of protein synthesis, cellular apoptosis and impaired virus propagation. ${ }^{121,167,168}$ Therefore, the OAS/ RNase L pathway represents a critical arm of IFN's antiviral effector mechanism against many viruses, including $\mathrm{HCV}{ }^{121}$ Depending on the specific RNA substrates and the extent of enzymatic activity, RNase L can block different types of viruses through different mechanisms, such as apoptosis, or through the 'suppressor of virus RNA' derived from cellular or viral RNA. ${ }^{168}$ Nevertheless, some members of the OAS family can exert antiviral activity independent of RNase L. ${ }^{169}$ 
The OAS system has been reported to exert anti-HCV effects through the RNase L pathway. The UA and UU dinucleotides within loops of predicted stem-loop structures in the viral RNA is prone to cleavage by RNase L (Table 1). ${ }^{110}$ Additionally, the sensitivity of HCV infection to IFN therapy correlates with the efficiency of RNase L-mediated viral RNA cleavage. ${ }^{110}$ The anti-HCV activity of OAS1 p46 and OAS3 p100 in the OAS family occurs in an RNase L-dependent fashion (Table 1). ${ }^{170}$ $\mathrm{HCV}$ replication is suppressed in HCVcc-infected Huh7 cells co-cultured with hepatic stellate cells (LX-2) treated with 5 'ppp-dsRNA or incubated with conditioned medium from LX2 cells stimulated with 5'ppp-dsRNA. ${ }^{125}$ In these HCVccinfected cells, the expression of OAS- 1 and MxA is upregulated. ${ }^{125}$ The two different domains in OAS-like a (OASLa), a major isoform in human liver that is induced by HCV, contribute to the antiviral activity. The N-terminal OAS homology domain, which lacks the cleavage activity, impairs cell proliferation as well as viral replication, whereas the C-terminal Ublike domain impedes HCV replication without affecting cell growth (Table 1). ${ }^{171}$

\section{ISG20}

The IFN-stimulated gene $20 \mathrm{kDa}$ protein (ISG20) has emerged as a second IFN-regulated RNase that inhibits RNA virus replication. ${ }^{172,173}$ ISG20, along with the closely related ISG20L1 and ISG20L2, belongs to the yeast RNA exonuclease 4 homolog subfamily within the DEDDh exonuclease family and members of this superfamily possess both RNase and DNase activities. ${ }^{173}$ The $3^{\prime}-5^{\prime}$ exonuclease activity of ISG20 demonstrates a greater preference for single-stranded RNA than for single-stranded DNA. ${ }^{173}$ ISG20 overexpression restricts infection by encephalomyocarditis virus, VSV, influenza virus (INFV), human immunodeficiency virus (HIV), YFV, picornavirus and HCV. ${ }^{172,173}$ ISG20 has been reported to impair HCV genotype 1b SGR replication in HEK293 cells (Table 1). ${ }^{146}$ In addition, ISG20 can hinder genotype 2a viral RNA replication either in SGR or HCVcc infection, and its anti-HCV effect is not shared with ISG20L1 and ISG20L2 (Table 1). ${ }^{172}$ Apart from degrading viral RNA through its $3^{\prime}-5^{\prime}$ exonuclease activity, ${ }^{146,172}$ the antiHCV mechanism of ISG20 in HCV replication remains poorly understood despite its possible action on cellular factors. ${ }^{173}$

\section{ADAR}

RNA-specific adenosine deaminase (ADAR) is constitutively expressed in normal cells as an inactive form. ${ }^{174}$ However, viral infection triggers the two mammalian ADAR genes, ADAR1 and $A D A R 2$, to express two active proteins, ADAR1 and ADAR2. ${ }^{174}$ ADAR catalyzes adenosine to inosine editing in RNAs that possess double-stranded structures. ${ }^{174,175}$ Because $\mathrm{I}$ is recognized as guanosine by RNA polymerase, A to I editing causes nucleotide substitution as well as dsRNA destabilization because of the reduced stability of I:U mismatch base pair compared with the normal base pair. ${ }^{174,175}$ The RNA editing ability of ADAR affects many biological processes, including viral replication and persistence, apoptosis, ion channel function and the posttranscriptional modification of genes. ${ }^{174,176}$ Only the
ADAR1 transcription level is induced by IFN treatment and by pathogen infections. ${ }^{177}$ In addition, ADAR1, but not ADAR2, affects the stability of HCV replicon RNA (Table 1). ${ }^{148}$

In HCV SGR replication, IFN- $\alpha$ treatment decreases viral RNA replication and concomitantly increases ADAR1 expression, suggesting that ADAR1 possesses an antiviral activity in the HCV RNA replicon. ${ }^{148}$ ADAR1 knockdown conversely increases the HCV replicon RNA. ${ }^{148}$ Loss of HCV RNA by ADAR1 may be due to several reasons. ${ }^{148}$ First, an I base-specific RNase might target mutated viral RNA. Second, the mutated RNA might lead to insufficient replication and genome instability. ${ }^{148}$ Third, the cellular mRNA involved in viral replication may also be targeted by ADAR1. Thus, the RNA editing ability of ADAR1 negatively affects HCV RNA replication, representing a potent strategy in anti-HCV therapy.

In sharp contrast, the replication of hepatitis delta virus (HDV) benefits from ADAR1 editing. ${ }^{178}$ The editing of HDV RNA by ADAR1 converts the UAG stop codon to a UIG tryptophan codon, allowing the synthesis of a larger HDV antigen. ${ }^{179}$ Without viral RNA editing, the HDV genome cannot be packaged into a virion. ${ }^{179}$ Nonetheless, ADAR overexpression increases RNA editing but decreases HDV replication. ${ }^{180}$

\section{IFN-inducible transmembrane protein (IFITM) family} IFITM family members, including IFITM1, IFITM2 and IFITM3, inhibit, in an IFITM-specific manner, the replication of diverse pathogenic membrane-enveloped viruses, including Marburg virus and Ebola (EBOV) filoviruses; severe acute respiratory coronavirus; HIV; Rift Valley fever virus (RVFV); respiratory syncytial virus; reovirus; flaviviruses, including DenV and WNV; and HCV. ${ }^{181-186}$ In contrast, IFITMs show no inhibitory effects on entry of amphotropic mouse leukemia virus, Machupo virus, Lassa virus and lymphocytic choriomeningitis virus. ${ }^{183}$

IFITMs are topologically located at different intracellular membrane compartments. IFITM2 and IFITM3, which are type II transmembrane proteins, are primarily localized to endosomes and lysosomes, ${ }^{187,188}$ whereas IFITM1 also localizes to the cell periphery. ${ }^{189,190}$ IFIT3 interacts with TBK1, IRF3 and other IFITM members and enhances IFN signaling. ${ }^{191,192}$

Lipid raft membranes, which are enriched in cholesterol and sphingolipids, play vital roles in cellular pathways and in virus entry, assembly and budding. ${ }^{193,194}$ Vesicle-associated membrane protein-associated protein A (VAPA) and oxysterolbinding protein (OSBP) modulate the intracellular trafficking and de novo synthesis of cholesterol. ${ }^{195}$ VAPA interacts with OSBP to regulate the transfer of cholesterol from the ER to other organelles. ${ }^{196,197}$ The regulation of intracellular cholesterol homeostasis, particularly in the endosomal compartment, is critical for the entry of viruses such as EBOV and Marburg viruses. ${ }^{198}$

IFITMs have been demonstrated to interfere with virus infection by blocking virus-endosome fusion (Table 1) ${ }^{183,184}$ presumably through the modification of cellular membrane properties, such as fluidity and spontaneous curvature. ${ }^{184,188,199}$ Amini-Bavil-Olyaee et al. ${ }^{188}$ demonstrated that the interaction 
of IFITM3 with VAPA antagonizes the association of VAPA with OSBP, thereby inducing the accumulation of cholesterol in multivesicular bodies and in late endosomes. The disruption of intracellular cholesterol homeostasis subsequently impairs the membrane fusion of intraluminal virion-containing vesicles and endosomes, resulting in a block of VSV release into the cytosol. ${ }^{188}$

Using immortalized human hepatocytes and Huh7 infection models, Raychoudhuri demonstrated that IFITM1 expression inhibits HCV replication but not at virus entry. ${ }^{200}$ Later, Wilkins et al. ${ }^{186}$ identified that IFITM1 is a hepatocyte tight junction protein whose antiviral action occurs through modification of the interactions of the HCV coreceptors CD81 and occludin, thereby inhibiting HCV entry (Table 1). ${ }^{186}$ This study represents an interesting mode of antiviral innate immunity; an ISG can exert its anti-HCV action by disrupting viral coreceptor associations.

\section{IFIT family}

The IFN-induced protein with tetratricopeptide repeats (IFITs) family represents a class of ISGs featured by their unique helix-turn-helix motifs, known as tetratricopeptide repeats. IFITs mediate a broad range of protein-protein interactions; in particular, the tetratricopeptide repeat motif is critical for modulating protein translational initiation and transport, cell proliferation and migration, virus replication, and antiviral signaling. ${ }^{201-204}$ Proteins in the IFIT family have been linked to IFN antiviral functions, including those against WNV and lymphocytic choriomeningitis virus. ${ }^{205}$ IFIT3 plays an important role in modulating innate immunity by bridging TBK1 to MAVS on mitochondria as IFIT3 expression facilitates the association of its tetratricopeptide repeat motif with the $\mathrm{N}$ terminus of TBK1, thereby enhancing IRF3-mediated gene expression. ${ }^{192}$

IFIT1, which is also known as ISG56, belongs to a family that also contains other stress-induced, structurally related proteins, P60, P58 and P54, in humans. IFIT1 acts as a negativefeedback regulator for Sendai virus-triggered induction of type 1 IFN antiviral signaling transduction, presumably through its interaction with the adapter protein STING and through disruption of the normal association between STING/MITA and MAVS or TBK $1 .{ }^{203}$ Moreover, IFIT1/2 preferentially targets mutants of poxvirus, coronavirus, and WNV that lack 2'-O methylation in their viral RNA cap, thereby rendering these mutant viruses unable to replicate. ${ }^{204}$ This study addresses the mechanism by which $2^{\prime}-\mathrm{O}$ methylation of the $5^{\prime}$ cap of viral RNA renders viruses insensitive to IFIT-mediated host innate antiviral activity.

Wang et al. ${ }^{147}$ demonstrated that IFIT1 mediates its IFN antiviral activity and blocks HCV RNA replication, presumably by targeting an eIF3-dependent step in viral IRES-mediated translation (Table 1). ${ }^{147}$ In immortalized human hepatocyte and Huh7 infection models, Raychoudhuri documented that IFIT1 expression inhibits HCV replication by suppressing HCV IRES-mediated transcription. ${ }^{200}$ Conversely, IFIT1 knockdown facilitates HCV replication. ${ }^{200}$ These results suggest that IFIT1 restricts HCV infection primarily at the viral translation/replication site.

\section{ISG15 and USP18}

Protein posttranslational modifications by Ub and UBL modifiers not only play important roles in numerous cellular processes, such as protein localization, interaction, activity and degradation, signal transduction, vesicular trafficking and DNA damage repair, ${ }^{206-208}$ but also modulate pathogen-host interactions, such as the viral replication cycle and the host antiviral response. ${ }^{208-210}$ ISG15, which was the first UBL protein modifier identified, ${ }^{211}$ is post-translationally attached via its $\mathrm{C}$ terminus to the lysine residues of ISGs and to hundreds of target proteins involved in different pathways. ${ }^{212,213}$ Similar to its Ub homolog, ISG15 is linked to proteins via a tightly regulated process known as 'ISGylation', and the activating E1 (Ube1L), conjugating E2 (UbcH8), and ligating E3 (CEB1) enzymes catalyze these sequential events. ${ }^{211,214}$ ISG15, together with its conjugation E3 ligase (CEB1) and its deconjugation enzyme USP18, are in the same ISG15/USP18 UBL pathway.

ISGylation modulates signal transduction pathways and host antiviral responses. ISG15 exerts its modulatory roles by inhibiting virus release, ISOylating viral proteins, or modifying host proteins. ${ }^{214}$ ISG15 targets many cellular proteins, including JAK1, STAT1 and many ISGs. Three antiviral effector molecules, IRF3, RIG-I and PKR, are also modified by ISGylation. ${ }^{214}$ Activated IRF3 is stabilized by ISGylation and therefore, positively regulates type I IFN signaling. ${ }^{215,216}$ The ISG15 conjugation-mediated reduction of the non-ISGylated RIG-I correlates with the reduced NDV-triggered IFN response. ${ }^{123}$ Additionally, viral RNA-independent PKR activation requires the ISGylation of PKR. ${ }^{217}$

ISG15 expression enhances IFN-mediated antiviral activity against many viruses, including HIV and SINV. ${ }^{214}$ Overexpressing ISG15 in IFN- $\alpha / \beta$ receptor knockout mice decreases SINV replication and protects the mice from SINV-induced lethality. ${ }^{218}$ ISG $15^{-1-}$ mice are more susceptible to infection by many RNA and DNA viruses, such as INFV and herpes simplex virus (HSV) type 1, and the protection effect of ISG15 from SINV infection is dependent on ISGylation. ${ }^{219}$ Lu et al. ${ }^{215}$ demonstrated that induction of ISG15 expression in NDV-infected cells counteracts the Ub-mediated degradation of IRF3 and enhances the NDV-mediated host innate antiviral response. Their findings revealed a feedback mechanism of ISG15 in enhanced antiviral immunity. Despite functioning as an antiviral molecule, ISGylation of the antiviral RIG-I enzyme inhibits IFN signaling in mouse embryonic fibroblast cells. ${ }^{123}$

Using the genotype 2a J6/Japanese fulminant hepatitis-1 chimeric HCV infectious model, Chen et al. ${ }^{220}$ unexpectedly found that ISG15 acts as a pro-HCV regulator because increased ISG15/ISGylation facilitates HCV production, whereas blocking ISGylation decreases virus production (Table 1). Moreover, knockdown of Ube1L, the E1 activating enzyme, inhibits HCV replication, particularly HCV egress, without affecting IFN-mediated ISG expression in HCV- 
infected cells. ${ }^{220}$ Using the HCV-Huh7.25.CD81 infection system, Arnaud et al. dissected the acute IFN response to HCV infection into early, PKR, and late, RIG-I, phases. ${ }^{221} \mathrm{HCV}$ infection rapidly induces the expression of many IRF3-dependent genes, including ISG15, through a PKR-dependent mechanism before the RIG-I phase, which recruits MAVS. ${ }^{221}$ Then, ISG15 induction blocks HCV RNA-mediated RIG-I activation by inhibiting RIG-I ubiquitination, thereby negatively controlling the RIG-I/MAVS pathway. ${ }^{221}$ These studies illustrate that HCV may exploit ISG15 to antagonize host innate immunity and to promote viral replication.

The deconjugation of USP 15 from its target proteins is catalyzed by USP 18 (mouse ortholog UBP43). ${ }^{222}$ USP 18 can function in both ISG15-dependent and ISG15-independent modes. USP18 was shown to bind to IFNAR2 and attenuate the JAKSTAT pathway, thereby negatively regulating IFN signaling (Table 1). ${ }^{223}$ Reduced USP18 expression results in increased antiviral activity against many viruses, such as SINV, hepatitis $\mathrm{B}$ virus and VSV, in USP18 knockout mice. ${ }^{218,223-225}$ USP18 knockdown is concomitant with increased cellular protein ISGylation, prolonged STAT1 tyrosine phosphorylation and enhanced ISG expression, thus greatly enhancing the antiHCV potency of IFN. ${ }^{226}$ All these studies suggest that USP18 disruption can impede its negative regulatory effect on IFN signaling, resulting in sustained JAK-STAT activity and antiviral activity. Consistent with these observations, Murray et $a .^{227}$ demonstrated that IFN- $\alpha$ signaling and ISG induction were greatly increased when UPS18 was knocked down in both HCV SGR- and HCVcc-infected Huh7 cells. However, USP18 knockdown did not have a significant effect on antiHCV activity. ${ }^{27}$ These observations suggest a slight dependency of IFN-mediated antiviral activity on USP18 activity. ${ }^{227}$

Additionally, USP18 upregulation is predictive of a nonsustainable viral response to IFN treatment. ${ }^{34,228,229}$ The expression levels of UPS18 and ISG15 increase in liver biopsy specimens from chronically HCV-infected patients who do not respond to IFN-based therapy, inferring that HCV hijacks the ISG15/USP15 pathway to evade the antiviral immune response and to facilitate its replication (Table 1). ${ }^{34,230}$ This observation also explains, at least partially, the failure of IFN-based treatments in non-responders, although non-responders express higher levels of ISGs, particularly ISG15, compared with IFN responders. ${ }^{34,230}$ Taken together, these findings demonstrate that USP18 is an attractive target for the development of anti-HCV therapeutics.

\section{Viperin}

Viperin, which stands for virus inhibitory protein, endoplasmic reticulum-associated, IFN-inducible, plays crucial roles in virus replication, signaling and the immune response. ${ }^{231,232}$ The viperin protein sequence is highly conserved, and all viperin homologs contain three functional domains: the amphipathic, N-terminal domain, which mediates ER and $\mathrm{LD}$ association; the central CxxxCxxC motif, which is functionally important for Fe-S cluster formation; and the highly conserved C-terminal domain, which is essential for antiviral activity. ${ }^{231-233}$ In addition to type I, type II and type III IFNs, dsDNA and dsRNA analogs, bacteria, lipopolysaccharide, poly(I:C) and a broad spectrum of DNA and RNA viruses can induce viperin expression. ${ }^{231,232,234}$ Viperin expression regulates many cellular functions, such as forming LDs and reducing membrane fluidity. ${ }^{231}$

Viperin possesses antiviral activity against diverse families of DNA and RNA viruses, including INFV, HIV, SINV, the flaviviruses Japanese encephalitis virus, DenV and WNV, and the hepacivirus HCV (Table 1). ${ }^{231,232,234}$ Viperin functions in different ways to defend against virus infections. For instance, viperin alters membrane fluidity by interacting with farnesyl diphosphate synthase, which is an enzyme essential for isoprenoid biosynthesis, thus disrupting the formation of lipid rafts, the sites of INFV budding, leading to interference with virus release from the cell surface. ${ }^{235}$ The induction of viperin into HIV-1-infected cells disrupts lipid rafts, causing viperin redistribution to CD81 compartments, where HIV-1 buds in human macrophages. ${ }^{236}$ The radical $S$-adenosyl-methionine enzymatic activity of viperin is required for the inhibition of HIV production. ${ }^{236}$ In cells infected with Japanese encephalitis virus, the antiviral function of viperin is attenuated due to its degradation by the proteasome-mediated protein degradation system. ${ }^{237}$ In contrast, viperin enhances human cytomegalovirus infection through its interaction with the viral mitochondrial inhibitor of apoptosis vMIA protein, resulting in viperin relocalization from the ER to mitochondria. ${ }^{238}$ In mitochondria, viperin interacts with the mitochondrial trifunctional protein and reduces cellular ATP generation, resulting in the disruption of the actin cytoskeleton and enhancement of the virus infection. $^{238}$

Viperin is upregulated in Huh7 cells transfected with either poly(I:C) or HCV RNA, ${ }^{239}$ and transient expression of viperin in HCV SGR replicating cells significantly decreases HCV replication. ${ }^{239}$ The putative radical $S$-adenosyl-methionine enzymatic activity of viperin is required for this anti-HCV activity. ${ }^{146}$ Helbig et al. ${ }^{240}$ further demonstrated that the restriction of HCV Cc replication by viperin depends on both the $\mathrm{N}$-terminal amphipathic $\alpha$-helix and the C-terminal domain. The anti-HCV function of viperin coincides with its binding to NS5A at the LD interface, whereas NS5A normally associates with the human homolog of the $33-\mathrm{kDa}$ vesicleassociated membrane protein-associated protein (hVAP-33), which is a pro-viral cellular factor, at the viral replication complex. ${ }^{239}$ The interaction of HCV NS5A with hVAP-33 was previously shown to be critical for the formation of the viral replication complex. ${ }^{52}$ Therefore, the association between viperin and hVAP-33 requires both of their C-terminal domains, which then disturbs the interaction of hVAP-33 with NS5A and inhibits HCV replication (Table 1). ${ }^{241}$ Together, these findings imply that viperin hinders viral RNA replication by perturbing the interaction between hVAP-33 and NS5A.

\section{$\mathrm{CH} 25 \mathrm{H}$}

By conducting bioinformatic analyses of murine bone marrowderived macrophages, Liu et al. showed that cholesterol-25- 
hydroxylase $(\mathrm{CH} 25 \mathrm{H})$, which is an IFN- $\alpha$ - and IFN- $\gamma$-stimulated ISG, can mitigate the replication of many membraneenveloped viruses, including HIV, VSV, HSV and murine $\gamma$-herpesvirus, and many pathogenic viruses, such as RVFV, EBOV, Russian spring-summer encephalitis virus and Nipah virus in vitro and in vivo. ${ }^{242}$ These viruses contain different structural characteristics in their fusion proteins. For instance, HIV and EBOV contain class I fusion peptides, RVFV and Russian spring-summer encephalitis virus harbor class II peptides, and VSV and HSV belong to class III fusion proteins. ${ }^{243,244}$ The broadly antiviral action of the $\mathrm{CH} 25 \mathrm{H}$ gene product is mediated by the ability of its enzymatic product, 25 hydroxycholesterol, to inhibit $\mathrm{pH}$-dependent and $\mathrm{pH}$-independent membrane fusion between cells and viruses, as typified by VSV and HIV, respectively (Table 1). ${ }^{242}$ This study not only demonstrates that IFN can confer an antiviral state to host and/ or target cells by inducing a natural oxysterol inhibitor but also suggests that modification of membrane oxysterols can be used as a potential antiviral approach. ${ }^{242}$ Determining whether this broad antiviral ISG can block HCV-mediated membrane fusion would be interesting.

\section{POTENTIAL FUNCTIONS OF EMERGING ISGS IDENTIFIED FROM GENOME-WIDE SIRNA SCREENS IN HCV INFECTION}

Several genome-wide siRNA screens were recently performed to identify ISGs or IFN-mediated effector genes (IEGs) that mediate IFN antiviral functions. These studies have identified many new ISGs or IEGs and have revealed interesting features of the actions of ISGs.

Using an overexpression screen approach, Schoggins et al. ${ }^{28}$ demonstrated that each virus exhibits a unique but partially overlapping profile of antiviral ISG expression. The expression levels of ISGs may vary depending on viral infection or on the time, dose, or cell type used for IFN treatment. ${ }^{28}$ In HCV infection, higher expression levels of 36 unique ISGs were found to correlate with a reduction in the HCV viral load. ${ }^{245}$

Schoggins et al. ${ }^{28}$ further observed that multiple ISG genes could target each viral species with a range of inhibitory activities. A set of effectors, including IRF1, C6orf150 (also known as MB21D1), heparanase, RIG-I, MDA5 and IFITM3, exert broad antiviral activities against different viruses, including HCV, YFV, WNV, chikungunya virus, Venezuelan equine encephalitis virus and HIV $-1{ }^{28}$ However, other effectors, such as DDX60, IFN-inducible proteins 44L and 6, IFITM2, MAPK kinasekinase 14, Moloney leukemia virus 10, nicotinamidephosphoribosyltransferase, OASL, receptor transporter protein 4 , three prime repair exonuclease 1 and protein unc-84 homolog B, display species-specific antiviral effector functions. ${ }^{28}$ These results also demonstrated that different ISGs can exert additive antiviral effects on virus replication. ${ }^{28}$

Remarkably, several ISGs, such as ADAR, family with sequence similarity 46 , member $\mathrm{C}$, lymphocyte antigen $6 \mathrm{E}$ and mucolipin-2, can enhance the replication of certain viruses. ${ }^{28}$ Certainly, further characterizing how these ISGs antagonize IFN-mediated antiviral functions and determining which steps of virus replication are targeted by these ISGs are important. These findings indicate the complexity of the type I IFN-mediated innate immune response in virus replication.

Performing a siRNA-based 'gain of function' screen, Metz et al. ${ }^{246}$ identified several new anti-HCV ISGs in addition to those previously reported anti-HCV ISGs. This study demonstrated that both IFN- $\alpha$ and IFN- $\gamma$ can upregulate the expression of several ISGs, including IFIT3, TRIM14, phospholipid scramblase 1 and inducible nitric oxide synthase 2. These ISGs possess anti-HCV activity, although the precise roles of these ISGs in HCV replication are not understood. ${ }^{246}$ This study also reported a substantial overlap in antiviral innate immune responses triggered by either cytokine. ${ }^{246}$ However, some ISGs are more specifically induced by IFN- $\alpha$ or by IFN- $\gamma$. For instance, phospholipid scramblase 1 and nitric oxide synthase 2 primarily function as IFN- $\gamma$-mediated anti-HCV effectors. ${ }^{246}$ Moreover, different ISGs function additively or synergistically to interfere with $\mathrm{HCV}$ infection, ${ }^{246}$ indicating that the combinatorial and concerted actions of multiple effectors mediate repression of HCV replication.

In addition to the signaling molecules involved in the IFN/ JAK-STAT/ISGpathway, the majority of genes identified by Fusco et al. are not transcriptionally activated by IFN. ${ }^{247}$ In contrast to the notion that ISGs target specific virus replication steps, some of these genes can exert IFN-mediated antiviral effects at multiple steps of the HCV replication cycle. ${ }^{247}$ For instance, dipeptidyl-peptidase 4/CD26/adenosine deaminase complexing protein 2 blocks virus entry, initial RNA replication, and amplified translation. MYST1 histone acetyltransferase inhibits HCV entry, translation, RNA replication and virion release, and protein phosphatase 3 , catalytic subunit, $\beta$ isoform (PPP3CB) impairs virus entry, initial RNA replication and subsequent translation. Taken together, these findings reveal that these IFN-insensitive IEGs, together with ISGs, constitute the host cellular genes mediating the antiviral activity of IFN against viral replication.

A functional genomic screen has shown that several new genes comprising the U4/U6.U5 tri-small nuclear ribonucleoprotein (snRNP) possess the ability to mediate IFN antiviral activity. ${ }^{248}$ U4/U6.U5 tri-snRNP is the major component of human spliceosome complexes involved in mRNA processing. ${ }^{249}$ This genomic screen demonstrated that squamous cell carcinoma antigen recognized by T cells (SART1) is a U4/ U6.U5 tri-snRNP-specific factor required for IFN- $\alpha$-mediated anti-HCV activity, although SART1 is not induced by IFN$\alpha^{248}$ The anti-HCV activity of SART1 acts by regulating the expression of ISGs, such as MxA, OAS and PKR, either in the presence or absence of exogenous IFN- $\alpha .{ }^{248}$ This genetic screen links an unappreciated role of RNA processing to the control of antiviral immunity.

\section{ROLES OF CELLULAR FACTORS INVOLVED IN HOST IMMUNITY IN HCV REPLICATION}

In this section, we discuss recent findings regarding the roles of several cellular factors and/or machinery involved in the immune response in modulating HCV replication. Although 
these determinants are not directly induced or activated by IFN, knowledge of their interplay with the host immune response will help to elucidate their effects on HCV infection. The functions of these cellular determinants in $\mathrm{HCV}$ infection are summarized in Table 2.

\section{IKKa}

HCV can co-opt an intrinsic innate pathway and hijack cellular lipid metabolism to facilitate its assembly. IKK $\alpha$ was initially identified as a critical factor for HCV replication in a genomewide RNA interference screen. ${ }^{250}$ Subsequently, HCV infection was shown to activate IKK $\alpha$ through the interaction of the viral genome 3'-UTR with DEAD box polypeptide 3, X-linked (DDX3X). ${ }^{251} \mathrm{IKK} \alpha$ translocates into the nucleus and induces the $\mathrm{CBP} / \mathrm{p} 300$-mediated expression of lipogenic genes, including sterol regulatory element-binding proteins, followed by the promotion of core-mediated LD formation and the enhancement of HCV assembly (Table 2). ${ }^{251}$

\section{MSR1}

Dansako demonstrated that upon HCV expression, class A scavenger receptor type 1 (MSR1) expressed on the plasma membrane of infected and adjacent uninfected cells can bind to dsRNA released from infected cells and mediate its endocytosis and transport to endosomes where the dsRNA is sensed by TLR3 and initiates a local antiviral IFN response to restrict HCV replication. ${ }^{252}$ The MSR1-mediated binding, transport, and release of dsRNA at the acidified endosome requires a stretch of conserved basic residues within the $\mathrm{C}$ terminus of the collagen superfamily domain of MSR $1 .{ }^{252}$ Therefore, MSR 1 acts as a key element for the TLR3-mediated PRR, thereby rendering both infected and uninfected hepatocytes refractory to HCV replication (Table 2).

\section{HMGB1}

HMGB1, which is an abundant nuclear protein that mediates activation of host immune responses and inflammation, represents a prototype damage-associated molecular pattern that participates in the pathogenesis of diverse pathogens. ${ }^{253,254}$ HMGB1 is passively released by cell injury or ischemia without pathogen invasion, but is actively secreted from stimulated immune cells, such as natural killer cells, macrophages and mature dendritic cells. ${ }^{253}$ Many types of TLRs, such as TLR2, TLR4 and TLR9, can act as receptors for HMGB1. ${ }^{253}$

The production of reactive oxygen species can mediate translocation from the nucleus to the cytoplasm and the subsequent release of HMGB1. ${ }^{253,255}$ Interestingly, it has been shown that HCV core and NS5A can trigger oxidative stress in infected cells. ${ }^{256-258}$ Jung et al. ${ }^{259}$ demonstrated that HCV infection causes the nuclear-to-cytoplasmic translocation of HMGB1 and its release into the extracellular milieu. TLR4 acts as a major component of the receptor complex that recognizes lipopolysaccharide LPS and plays a role in the production of pro-inflammatory cytokines and antiviral IFNs via signaling MyD88 and the TLR adapter protein TRIF. ${ }^{260}$ Jung et al. ${ }^{259}$ also demonstrated that HMGB1 interacts with TLR4 to activate IFN signaling (Table 2). Because HMGB1 is present at higher levels in the sera of patients with chronic hepatitis and cirrhosis compared with those detected in control individuals, ${ }^{261}$ the results of Jung et al. may help to elucidate the potential inhibitory action of HMGB1 in HCV propagation in chronically HCV-infected patients. ${ }^{259}$

\section{Autophagy}

Autophagy is a conserved 'self-eating' process that engulfs and delivers cytoplasmic cargos and invading pathogens within double- or multiple-membrane autophagosomal structures to lysosomes for degradation. ${ }^{262-265}$ The purpose of autophagic induction is to maintain cellular homeostasis in the host when the host undergoes extracellular or intracellular stresses. Autophagy plays pivotal roles in the stress response, nutrient deprivation, damaged organelles, unfolded protein aggregation, intracellular quality control and cell death. ${ }^{262-265}$ The autophagic process requires two UBL conjugation complexes:

\section{Table 2 Functions of cellular determinants involved in immune responses during HCV replication}

\begin{tabular}{ll}
\hline Immune regulator & Function in HCV replication \\
\hline IKK- $\alpha$ & $\begin{array}{l}\text { Promotion of HCV assembly by IKK } \alpha \text { through the interaction of the viral 3'-UTR with DDX3X, which promotes the } \\
\text { MRS1 }\end{array}$ \\
& $\begin{array}{l}\text { Restriction of HCV replication by MSR1 through its mediation of the recognition of viral dsRNA produced in } \\
\text { neighboring cells by TLR3 }\end{array}$ \\
HMGB1 & Inhibition of HCV infection by activating IFN signaling mediated by TLR4 through an interaction with HMGB1 \\
Autophagy & Promotion of HCV RNA replication through the suppression of innate antiviral immunity by autophagy \\
& Protection of cells from HCV-infected apoptotic death by autophagy by downregulating innate immunity and ISG \\
& production \\
IRGM & Enhanced HCV replication and elimination of damaged mitochondria by PINK- and Parkin-dependent mitophagy \\
miR-21 & Inhibition of MyD88 and IRAK1 expression by miR-21, leading to the suppression of TLR signaling and an increase \\
& in HCV viral replication \\
\hline
\end{tabular}

Abbreviations: DDX, DExD/H box RNA helicase; dsRNA, double-stranded RNA; HCV, hepatitis C virus; HMGB1, high-mobility group box 1; IFN, interferon; IKK, IKB kinase-related kinase; IRAK, IL-1 receptor-associated kinase; IRGM, immunity-related GTPase family M; ISG, IFN-stimulated gene; LD, lipid droplet; miR, microRNA; MSR, class A scavenger receptor type; MyD88, myeloid differentiation proinflammatory response 88; TLR, Toll-like receptor; UTR, untranslated region. 
autophagy-related gene (ATG) 12-ATG5-ATG16L and microtubule-associated protein 1 light chain 3-phosphatidylethanolamine. ${ }^{262,266}$

Autophagy has emerged as an immune regulator that commands the innate and adaptive immune responses against intracellular viruses. ${ }^{267-271}$ Autophagy also participates in the modulation of virus-host interactions. In contrast, viruses can subvert the host autophagic pathway to potentiate their own growth. ${ }^{272,273}$ Analogously, HCV is able to subvert the host autophagic machinery and enhance viral growth, including RNA replication, ${ }^{274}$ translation of the incoming viral RNA genome ${ }^{275}$ and the release of infectious viruses (Table 2). ${ }^{276}$

Two laboratories have independently demonstrated that $\mathrm{HCV}$ can activate autophagy via ER stress-mediated induction of the UPR and that UPR-autophagy is required for HCV replication. ${ }^{7,277}$ HCV NS3, NS4B, NS5A and NS5B have also been implicated in the induction of autophagy. ${ }^{12,27}$ Huang et al. ${ }^{278}$ showed that HCV induces ER stress and inhibits the AKTtuberous sclerosis-mTOR complex 1 signaling pathway, resulting in autophagy activation. In contrast, Shrivastava et al. ${ }^{279}$ demonstrated that HCV induces autophagy by stimulating Beclin mRNA expression and by activating mTOR signaling, which may enhance hepatocyte growth.

Ke and Chen ${ }^{277}$ demonstrated that in the context of HCV infection or without HCV infection, activation of the UPR and autophagy downregulates innate immunity; in contrast, disruption of the UPR and autophagy upregulates innate immunity. These results demonstrate that HCV hijacks UPR and autophagy to stimulate viral RNA replication by suppressing immune antiviral immunity. The UPR-autophagy pathway represents a unique mode of reversible control in the innate immunity capacity in target cells. ${ }^{10,27}$ Subsequently, Shrivastava et al. ${ }^{280}$ found that Beclin or ATG7 gene silencing in genotype 1a H77 strain HCV-infected immortalized human hepatocyte upregulates IFN signaling and ISG expression, which are concurrent with apoptotic cell death. Together, the results from these two groups suggest that autophagy may protect HCV-infected cells from the damage caused by excessive IFN antiviral stimulation, thereby promoting HCV RNA replication.

Furthermore, a specific mode of autophagy, termed 'mitophagy', was recently reported to play a critical role in HCV replication and in the elimination of damaged mitochondria in infected cells in a Parkin-dependent manner. ${ }^{281}$ Knockdown of Parkin and Pink gene expression suppresses viral RNA replication (Table 2) ${ }^{281}$ These results suggest a critical role for mitophagy in HCV replication. Nevertheless, the molecular basis for the roles of autophagy and mitophagy in suppressing innate antiviral immunity in HCV infection has yet to be investigated.

\section{IRGM}

A recent study has demonstrated that many different families of RNA viruses can target the autophagy network to promote viral growth. ${ }^{282}$ Among these targets is IRGM, which modulates autophagy by interacting with many autophagy-associated proteins, such as ATG5, ATG10 and light chain 3C. Strikingly, IRGM knockdown impairs autophagy induced by many viruses, such as $\mathrm{HCV}, \mathrm{MeV}$ and $\mathrm{HIV}-1$, resulting in mitigated viral replication (Table 2). ${ }^{282}$ Moreover, the $\mathrm{C}$ protein of $\mathrm{MeV}$, NS3 of HCV, and Nef of HIV-1 were shown to induce autophagy by interacting with IRGM. These results suggest that RNA viruses have evolved to use a common strategy to target a critical molecule in autophagy to benefit their growth.

\section{miR-21}

MicroRNA is a class of endogenous small non-coding RNAs that bind to the $3^{\prime}$-UTR of target mRNAs to control gene expression. ${ }^{283}$ microRNAs also participate in innate and adaptive immunity response by binding to their complementarily mRNAs and regulating the expression and translation of their target genes. ${ }^{284}$ For example, miR-155 regulates the host antiviral immune response by promoting type I IFN, whereas miR16 enhances mRNA degradation. ${ }^{285}$

miR-21 was shown to be upregulated in liver samples from hepatocellular carcinoma patients and in HCV-infected cells. ${ }^{286}$ During HCV infection, miR-21 expression is activated by the PKCe/JNK/cJun and PKC $\alpha /$ ERK/cFos pathways. ${ }^{287}$ cJun and cFos form the AP-1 protein, which binds to the miR-21 promoter and activates miR-21 expression. ${ }^{287}$ miR-21 upregulation was shown to suppress the expression of MyD88 and IRAK1, which are two genes involved in the TLR signaling cascade, thereby repressing the production of type I IFN and ISG and promoting HCV replication (Table 2). ${ }^{287}$ These results indicate that $\mathrm{HCV}$ usurps miR-21 to enhance its replication. Likewise, miR-21 also increases the production of HIV, VSV and enterovirus 71 by suppressing type I IFN production. ${ }^{287}$

\section{CONCLUSIONS}

The mechanisms by which viruses and cells coevolve and the tactics each party employs to establish the dynamic equilibrium are emerging as a fascinating area in HCV-host interaction research. Previous studies that aimed to understand the HCV cell coevolution process have revealed several interesting aspects of virus-host cell interactions, such as ER stress, UPR, autophagy and innate antiviral immunity responses in HCV replication. ${ }^{11,12,27}$ Further determining how the virus-cell interplay subsequently reshapes the host defense mechanisms and how virus replication is modulated in response to these cellular stresses will be important for gaining a complete understanding of the molecular basis of the HCV-host interaction in the pathogenesis of HCV infection.

Viral infection can trigger the IFN-mediated frontline host defense mechanism, including the production of a wide range of ISGs to limit virus replication. Many studies have also hitherto demonstrated that some of the identified ISGs can exert broad antiviral activities against a diverse spectrum of viruses, whereas other ISGs may have virus type-specific functions. The majority of studied ISGs mediate IFN antiviral activities, acting as negative regulators in virus replication. Strikingly, some ISGs function as negative modifiers in the innate immune response, thereby promoting virus replication. Nevertheless, the modes of action of most of the ISGs remain unclear. Although most identified ISGs target individual steps of virus replication, 
some ISGs seem to act at multiple stages of the virus replication cycle. Determining the mechanisms by which these ISGs function at different steps of the virus replication cycle would be interesting.

Current studies have indicated that different types of IFNs may substantially overlap in mediating their innate immune response by activating the same set of ISGs. However, the induction of some ISGs may be unique to only one type of IFN, indicating the specificity in the induction of these ISGs by IFNs. Clearly, different ISGs can additively or synergistically suppress HCV replication, suggesting that inhibiting HCV replication depends on the combinatorial effects of individual ISGs induced by IFN under the specific context of HCV infection. Therefore, IFN-mediated suppression of HCV replication is not caused by a single ISG but rather by the concerted actions of multiple ISGs.

Moreover, gene expression profiling of hepatocytes from chronically HCV-infected patients treated with IFN has consistently shown differences between IFN-responders and IFNnon-responders. For instance, the levels of specific ISGs, such as ISG15 and USP18, and viral sensors, such as RIG-I, MDA5 and laboratory of genetics and physiology-2, are upregulated in patients with non-sustained virological responses compared with patients with sustained virological responses. ${ }^{34,228}$ Therefore, profiling gene expression for cytoplasmic viral sensors and related regulators involved in the innate antiviral immune response can identify new ISGs that can be used as markers for predicting the clinical outcome of IFN therapy.

In conclusion, the emergence of complexity in the highly pleiotropic type I IFN system in HCV infection reveals that the host has evolved to erect multiple checkpoints for anti$\mathrm{HCV}$ innate immune surveillance to ensure that HCV is under tight control at all times, even when a single effector fails to confer antiviral activity, without drastically downgrading the overall efficacy of the IFN treatment. Therefore, further deciphering which ISGs and/or IEGs are induced by IFNs upon $\mathrm{HCV}$ infection and the specificity and action of these ISGs and other cellular immune regulators on HCV replication will not only provide insights into how IFN functions to obstruct HCV replication but will also reveal novel cellular targets against which effective and efficacious anti-HCV therapeutics can be developed.

\section{ACKNOWLEDGEMENTS}

This study was supported by research grants from the Ministry of Science and Technology (101-2320-B-001-022-MY3) and Academia Sinica, Taipei. This manuscript was edited for the English language by American Journal Experts (AJE).

1 Lavanchy D. The global burden of hepatitis C. Liver Int 2009; 29(Suppl 1): 74-81.

2 Chisari FV. Unscrambling hepatitis C virus-host interactions. Nature 2005; 436: 930-932.

3 Moradpour D, Penin F, Rice CM. Replication of hepatitis C virus. Nat Rev Microbiol 2007; 5: 453-463.
4 Lauletta G, Russi S, Conteduca V, Sansonno L. Hepatitis C virus infection and mixed cryoglobulinemia. Clin Dev Immunol 2012; 2012: 502156.

5 Wakita T, Pietschmann T, Kato T, Date T, Miyamoto M, Zhao Z et al. Production of infectious hepatitis $\mathrm{C}$ virus in tissue culture from a cloned viral genome. Nat Med 2005; 11: 791-796.

6 Zhong J, Gastaminza P, Chung J, Stamataki Z, Isogawa M, Cheng G et al. Persistent hepatitis $C$ virus infection in vitro: coevolution of virus and host. J Virol 2006; 80: 11082-11093.

7 Sir D, Liang C, Chen WL, Jung JU, Ou JH. Perturbation of autophagic pathway by hepatitis $C$ virus. Autophagy $2008 ; 4: 830-831$.

8 Dreux M, Chisari FV. Viruses and the autophagy machinery. Cell Cycle 2010; 9: 1295-1307.

9 Dreux M, Chisari FV. Impact of the autophagy machinery on hepatitis C virus infection. Viruses 2011; 3: 1342-1357.

$10 \mathrm{Ke}$ PY, Chen SS. Autophagy: a novel guardian of HCV against innate immune response. Autophagy 2011; 7: 533-535.

11 Ke PY, Chen SS. Hepatitis C virus and cellular stress response: implications to molecular pathogenesis of liver diseases. Viruses 2012; 4: 2251-2290.

12 Ke PY, Chen SS. Autophagy in hepatitis C virus-host interactions: potential roles and therapeutic targets for liver-associated diseases. World J Gastroenterol 2014; 20: 5773-5793.

13 Horner SM, Gale M Jr. Regulation of hepatic innate immunity by hepatitis C virus. Nat Med 2013; 19: 879-888.

14 Park SH, Rehermann B. Immune responses to HCV and other hepatitis viruses. Immunity 2014; 40: 13-24.

15 Kawai T, Akira S. Toll-like receptor and RIG-I-like receptor signaling. Ann NY Acad Sci 2008; 1143: 1-20.

16 Katze MG, Fornek JL, Palermo RE, Walters KA, Korth MJ. Innate immune modulation by RNA viruses: emerging insights from functional genomics. Nat Rev Immunol 2008; 8: 644-654.

17 Hoofnagle JH, Mullen KD, Jones DB, Rustgi V, Di Bisceglie A, Peters $M$ et al. Treatment of chronic non-A, non- $B$ hepatitis with recombinant human alpha interferon. A preliminary report. $N$ Eng/ J Med 1986; 315: 1575-1578.

18 Kawai T, Akira S. Innate immune recognition of viral infection. Nat Immunol 2006; 7: 131-137.

19 Horner SM. Activation and evasion of antiviral innate immunity by hepatitis C virus. J Mol Biol 2014; 426: 1198-1209.

20 Saito T, Gale M Jr. Regulation of innate immunity against hepatitis C virus infection. Hepatol Res 2008; 38: 115-122.

21 Lemon SM. Induction and evasion of innate antiviral responses by hepatitis C virus. J Biol Chem 2010; 285: 22741-22747.

22 Saito T, Owen DM, Jiang F, Marcotrigiano J, Gale M Jr. Innate immunity induced by composition-dependent RIG-I recognition of hepatitis C virus RNA. Nature 2008; 454: 523-527.

23 Gale M Jr, Foy EM. Evasion of intracellular host defence by hepatitis C virus. Nature 2005; 436: 939-945.

24 Liu HM, Gale M. Hepatitis C virus evasion from RIG-I-dependent hepatic innate immunity. Gastroenterol Res Pract 2010; 2010: 548390.

25 Wohnsland A, Hofmann WP, Sarrazin C. Viral determinants of resistance to treatment in patients with hepatitis C. Clin Microbiol Rev 2007; 20: 23-38.

26 Li K, Lemon SM. Innate immune responses in hepatitis $\mathrm{C}$ virus infection. Semin Immunopathol 2013; 35: 53-72.

27 Chen SS, Ke PY. Suppression of innate antiviral immunity after hepatitis $C$ virus infection: role of the unfolded protein response and autophagy. In:Hayat MA (ed.) Autophagy: Cancer, Other Pathologies, Inflammation, Immunity, Infection, and Aging. Volume 2: Role in General Diseases. Amsterdam: Academic Press, 2014: 137-159.

28 Schoggins JW, Wilson SJ, Panis M, Murphy MY, Jones CT, Bieniasz P et al. A diverse range of gene products are effectors of the type I interferon antiviral response. Nature 2011; 472: 481-485.

29 Yan N, Chen ZJ. Intrinsic antiviral immunity. Nat Immunol 2012; 13: 214-222.

30 Smith DB, Bukh J, Kuiken C, Muerhoff AS, Rice CM, Stapleton JT et al. Expanded classification of hepatitis $C$ virus into 7 genotypes 
and 67 subtypes: updated criteria and genotype assignment web resource. Hepatology 2014; 59: 318-327.

31 Simmonds P, Bukh J, Combet C, Deleage G, Enomoto N, Feinstone S et al. Consensus proposals for a unified system of nomenclature of hepatitis C virus genotypes. Hepatology 2005; 42: 962-973.

32 Messina JP, Humphreys I, Flaxman A, Brown A, Cooke GS, Pybus OG et al. Global distribution and prevalence of hepatitis $C$ virus genotypes. Hepatology 2014; 2014 Jul 28. doi: 10.1002/ hep.27259. [Epub ahead of print].

33 Averhoff FM, Glass N, Holtzman D. Global burden of hepatitis C: considerations for healthcare providers in the United States. Clin Infect Dis 2012; 55(Suppl 1): S10-S15.

34 Chen L, Borozan I, Feld J, Sun J, Tannis LL, Coltescu C et al. Hepatic gene expression discriminates responders and nonresponders in treatment of chronic hepatitis C viral infection. Gastroenterology 2005; 128: 1437-1444.

35 Zein NN, Rakela J, Krawitt EL, Reddy KR, Tominaga T, Persing DH. Hepatitis $C$ virus genotypes in the United States: epidemiology, pathogenicity, and response to interferon therapy. Collaborative Study Group. Ann Intern Med 1996; 125: 634-639.

36 Chao DT, Abe K, Nguyen MH. Systematic review: epidemiology of hepatitis $C$ genotype 6 and its management. Aliment Pharmacol Ther 2011; 34: 286-296.

37 Ramalho F. Hepatitis C virus infection and liver steatosis. Antiviral Res 2003; 60: 125-127.

38 Zein NN. Clinical significance of hepatitis C virus genotypes. Clin Microbiol Rev 2000; 13: 223-235.

39 Pawlotsky JM. Treatment failure and resistance with direct-acting antiviral drugs against hepatitis C virus. Hepatology 2011; 53: 1742-1751.

40 Han JH, Shyamala V, Richman KH, Brauer MJ, Irvine B, Urdea MS et al. Characterization of the terminal regions of hepatitis $C$ viral RNA: identification of conserved sequences in the $5^{\prime}$ untranslated region and poly(A) tails at the $3^{\prime}$ end. Proc Natl Acad Sci USA 1991; 88: 1711-1715.

41 Jones CT, Murray CL, Eastman DK, Tassello J, Rice CM. Hepatitis C virus $\mathrm{p} 7$ and NS2 proteins are essential for production of infectious virus. J Virol 2007; 81: 8374-8383.

42 Jirasko V, Montserret R, Appel N, Janvier A, Eustachi L, Brohm C et al. Structural and functional characterization of nonstructural protein 2 for its role in hepatitis $\mathrm{C}$ virus assembly. J Biol Chem 2008; 283: 28546-28562.

43 Phan T, Beran RK, Peters C, Lorenz IC, Lindenbach BD. Hepatitis C virus NS2 protein contributes to virus particle assembly via opposing epistatic interactions with the E1-E2 glycoprotein and NS3-NS4A enzyme complexes. J Virol 2009; 83: 8379-8395.

44 Yi M, Ma Y, Yates J, Lemon SM. Trans-complementation of an NS2 defect in a late step in hepatitis $\mathrm{C}$ virus (HCV) particle assembly and maturation. PLoS Pathog 2009; 5: e1000403.

45 Dentzer TG, Lorenz IC, Evans MJ, Rice CM. Determinants of the hepatitis $C$ virus nonstructural protein 2 protease domain required for production of infectious virus. J Virol 2009; 83: 12702-12713.

46 Ma Y, Yates J, Liang Y, Lemon SM, Yi M. NS3 helicase domains involved in infectious intracellular hepatitis $C$ virus particle assembly. J Virol 2008; 82: 7624-7639.

47 Appel N, Zayas M, Miller S, Krijnse-Locker J, Schaller T, Friebe P et al. Essential role of domain III of nonstructural protein $5 \mathrm{~A}$ for hepatitis C virus infectious particle assembly. PLoS Pathog 2008; 4: e1000035.

48 Masaki T, Suzuki R, Murakami K, Aizaki H, Ishii K, Murayama A et al. Interaction of hepatitis $C$ virus nonstructural protein $5 \mathrm{~A}$ with core protein is critical for the production of infectious virus particles. $J$ Virol 2008; 82: 7964-7976.

49 Agnello V, Abel G, Elfahal M, Knight GB, Zhang QX. Hepatitis C virus and other Flaviviridae viruses enter cells via low density lipoprotein receptor. Proc Natl Acad Sci USA 1999; 96: 1276612771.

50 Lindenbach BD, Rice $C M$. The ins and outs of hepatitis $C$ virus entry and assembly. Nat Rev Microbiol 2013; 11: 688-700.
51 El-Hage N, Luo G. Replication of hepatitis C virus RNA occurs in a membrane-bound replication complex containing nonstructural viral proteins and RNA. J Gen Virol 2003; 84: 2761-2769.

52 Gao L, Aizaki H, He JW, Lai MM. Interactions between viral nonstructural proteins and host protein hVAP-33 mediate the formation of hepatitis C virus RNA replication complex on lipid raft. J Virol 2004; 78: 3480-3488.

53 Martin S, Parton RG. Lipid droplets: a unified view of a dynamic organelle. Nat Rev Mol Cell Biol 2006; 7: 373-378.

54 Miyanari Y, Atsuzawa K, Usuda N, Watashi K, Hishiki T, Zayas M et al. The lipid droplet is an important organelle for hepatitis $C$ virus production. Nat Cell Biol 2007; 9: 1089-1097.

55 Boulant S, Montserret R, Hope RG, Ratinier M, Targett-Adams P, Lavergne JP et al. Structural determinants that target the hepatitis $C$ virus core protein to lipid droplets. J Biol Chem 2006; 281: 2223622247.

56 Lai CK, Jeng KS, Machida K, Lai MM. Association of hepatitis C virus replication complexes with microtubules and actin filaments is dependent on the interaction of NS3 and NS5A. J Virol 2008; 82: 8838-8848.

57 Steinmann E, Penin F, Kallis S, Patel AH, Bartenschlager R, Pietschmann T. Hepatitis $C$ virus $p 7$ protein is crucial for assembly and release of infectious virions. PLoS Pathog 2007; 3: e103.

58 Atoom AM, Taylor NG, Russell RS. The elusive function of the hepatitis C virus p7 protein. Virology 2014; 462-463: 377-387.

59 Griffin SD, Beales LP, Clarke DS, Worsfold O, Evans SD, Jaeger J et al. The $\mathrm{p} 7$ protein of hepatitis $C$ virus forms an ion channel that is blocked by the antiviral drug, Amantadine. FEBS Lett 2003; 535: 34-38.

60 Steinmann E, Whitfield T, Kallis S, Dwek RA, Zitzmann N, Pietschmann $\mathrm{T}$ et al. Antiviral effects of amantadine and iminosugar derivatives against hepatitis C virus. Hepatology 2007; 46: 330-338.

61 Gentzsch J, Brohm C, Steinmann E, Friesland M, Menzel N, Vieyres G et al. hepatitis c Virus p7 is critical for capsid assembly and envelopment. PLoS Pathog 2013; 9: e1003355.

62 Sen GC. Viruses and interferons. Annu Rev Microbiol 2001; 55 : 255-281.

63 Randall RE, Goodbourn S. Interferons and viruses: an interplay between induction, signalling, antiviral responses and virus countermeasures. J Gen Virol 2008; 89: 1-47.

64 Levy DE, Marie IJ, Durbin JE. Induction and function of type I and III interferon in response to viral infection. Curr Opin Virol 2011; 1: 476-486

65 Katze MG, He Y, Gale M Jr. Viruses and interferon: a fight for supremacy. Nat Rev Immunol 2002; 2: 675-687.

66 Wei X, Jia ZS, Lian JQ, Zhang Y, Li J, Ma L et al. Inhibition of hepatitis $C$ virus infection by interferon-gamma through downregulating claudin-1. J Interferon Cytokine Res 2009; 29: 171-178.

67 Thomas E, Gonzalez VD, Li Q, Modi AA, Chen W, Noureddin M et al. $\mathrm{HCV}$ infection induces a unique hepatic innate immune response associated with robust production of type III interferons. Gastroenterology 2012; 142: 978-988.

68 Rehermann B. Pathogenesis of chronic viral hepatitis: differential roles of T cells and NK cells. Nat Med 2013; 19: 859-868.

69 Takeuchi O, Akira S. Innate immunity to virus infection. Immunol Rev 2009; 227: 75-86.

70 Xagorari A, Chlichlia K. Toll-like receptors and viruses: induction of innate antiviral immune responses. Open Microbiol J 2008; 2: 4959.

71 Loo YM, Owen DM, Li K, Erickson AK, Johnson CL, Fish PM et al. Viral and therapeutic control of IFN-beta promoter stimulator 1 during hepatitis C virus infection. Proc Natl Acad Sci USA 2006; 103: 6001-6006.

72 Kato H, Takeuchi O, Sato S, Yoneyama M, Yamamoto M, Matsui K et al. Differential roles of MDA5 and RIG-I helicases in the recognition of RNA viruses. Nature 2006; 441: 101-105.

73 Myong S, Cui S, Cornish PV, Kirchhofer A, Gack MU, Jung JU et al. Cytosolic viral sensor RIG-I is a 5'-triphosphate-dependent 
translocase on double-stranded RNA. Science 2009; 323: 10701074.

74 Liu HM, Loo YM, Horner SM, Zornetzer GA, Katze MG, Gale M Jr. The mitochondrial targeting chaperone $14-3-3$ regulates a RIG-I translocon that mediates membrane association and innate antiviral immunity. Cell Host Microbe 2012; 11: 528-537.

75 Heim MH. HCV innate immune responses. Viruses 2009; 1: 10731088.

76 Meylan E, Curran J, Hofmann K, Moradpour D, Binder M, Bartenschlager $\mathrm{R}$ et al. Cardif is an adaptor protein in the RIG-I antiviral pathway and is targeted by hepatitis $C$ virus. Nature 2005; 437: 1167-1172.

77 Shuai K, Liu B. Regulation of JAK-STAT signalling in the immune system. Nat Rev Immunol 2003; 3: 900-911.

78 Shimoike T, Koyama C, Murakami K, Suzuki R, Matsuura Y, Miyamura $\mathrm{T}$ et al. Down-regulation of the internal ribosome entry site (IRES)-mediated translation of the hepatitis $C$ virus: critical role of binding of the stem-loop IIId domain of IRES and the viral core protein. Virology 2006; 345: 434-445.

79 Lin W, Kim SS, Yeung E, Kamegaya Y, Blackard JT, Kim KA et al. Hepatitis $C$ virus core protein blocks interferon signaling by interaction with the STAT1 SH2 domain. J Virol 2006; 80: 92269235.

80 Bode JG, Ludwig S, Ehrhardt C, Albrecht U, Erhardt A, Schaper F et al. IFN-alpha antagonistic activity of HCV core protein involves induction of suppressor of cytokine signaling-3. FASEB J 2003; 17: 488-490.

81 Funaoka Y, Sakamoto N, Suda G, Itsui Y, Nakagawa M, Kakinuma S et al. Analysis of interferon signaling by infectious hepatitis $C$ virus clones with substitutions of core amino acids 70 and 91 . J Virol 2011; 85: 5986-5994.

82 Ciccaglione AR, Stellacci E, Marcantonio C, Muto V, Equestre M, Marsili $\mathrm{G}$ et al. Repression of interferon regulatory factor 1 by hepatitis $C$ virus core protein results in inhibition of antiviral and immunomodulatory genes. J Virol 2007; 81: 202-214.

83 Vossen MT, Westerhout EM, Soderberg-Naucler C, Wiertz EJ. Viral immune evasion: a masterpiece of evolution. Immunogenetics 2002; 54: 527-542.

84 Taylor DR, Shi ST, Romano PR, Barber GN, Lai MM. Inhibition of the interferon-inducible protein kinase PKR by HCV E2 protein. Science 1999; 285: 107-110.

85 Taylor DR, Shi ST, Lai MM. Hepatitis C virus and interferon resistance. Microbes Infect 2000; 2: 1743-1756.

86 Horner SM, Park HS, Gale M Jr. Control of innate immune signaling and membrane targeting by the hepatitis $C$ virus NS3/4A protease are governed by the NS3 helix $\alpha_{0}$. J Virol 2012; 86: 3112-3120.

87 Brass V, Berke JM, Montserret R, Blum HE, Penin F, Moradpour D. Structural determinants for membrane association and dynamic organization of the hepatitis C virus NS3-4A complex. Proc NatI Acad Sci USA 2008; 105: 14545-14550.

88 Li XD, Sun L, Seth RB, Pineda G, Chen ZJ. Hepatitis C virus protease NS3/4A cleaves mitochondrial antiviral signaling protein off the mitochondria to evade innate immunity. Proc Natl Acad Sci USA 2005; 102: 17717-17722.

89 Li K, Foy E, Ferreon JC, Nakamura M, Ferreon AC, Ikeda M et al. Immune evasion by hepatitis $C$ virus NS3/4A protease-mediated cleavage of the Toll-like receptor 3 adaptor protein TRIF. Proc Natl Acad Sci USA 2005; 102: 2992-2997.

90 Bellecave P, Sarasin-Filipowicz M, Donze O, Kennel A, Gouttenoire $\mathrm{J}$, Meylan E et al. Cleavage of mitochondrial antiviral signaling protein in the liver of patients with chronic hepatitis $C$ correlates with a reduced activation of the endogenous interferon system. Hepatology 2010; 51: 1127-1136.

91 Jiang Z, Mak TW, Sen G, Li X. Toll-like receptor 3-mediated activation of NF-KB and IRF3 diverges at Toll-IL-1 receptor domain-containing adapter inducing IFN- $\beta$. Proc Natl Acad Sci USA 2004; 101: 3533-3538.

92 Ishikawa H, Barber GN. STING is an endoplasmic reticulum adaptor that facilitates innate immune signalling. Nature 2008; 455: 674678.
93 Tanaka Y, Chen ZJ. STING specifies IRF3 phosphorylation by TBK1 in the cytosolic DNA signaling pathway. Sci Signal 2012; 5: ra20.

94 Ishikawa H, Ma Z, Barber GN. STING regulates intracellular DNAmediated, type I interferon-dependent innate immunity. Nature 2009; 461: 788-792.

95 Aguirre S, Maestre AM, Pagni S, Patel JR, Savage T, Gutman D et al. DENV inhibits type I IFN production in infected cells by cleaving human STING. PLoS Pathog 2012; 8: e1002934.

96 Ding Q, Cao X, Lu J, Huang B, Liu YJ, Kato N et al. Hepatitis C virus NS4B blocks the interaction of STING and TBK1 to evade host innate immunity. J Hepatol 2013; 59: 52-58.

97 Nitta S, Sakamoto N, Nakagawa M, Kakinuma S, Mishima K, Kusano-Kitazume A et al. Hepatitis C virus NS4B protein targets STING and abrogates RIG-I-mediated type I interferon-dependent innate immunity. Hepatology 2013; 57: 46-58.

98 Tanji Y, Kaneko T, Satoh S, Shimotohno K. Phosphorylation of hepatitis C virus-encoded nonstructural protein NS5A. J Virol 1995; 69: 3980-3986.

99 Reed KE, Xu J, Rice CM. Phosphorylation of the hepatitis C virus NS5A protein in vitro and in vivo: properties of the NS5A-associated kinase. J Virol 1997; 71: 7187-7197.

100 Huang Y, Staschke K, de Francesco R, Tan SL. Phosphorylation of hepatitis $C$ virus NS5A nonstructural protein: a new paradigm for phosphorylation-dependent viral RNA replication? Virology 2007; 364: 1-9.

101 Neddermann P, Quintavalle M, Di Pietro C, Clementi A, Cerretani M, Altamura $S$ et al. Reduction of hepatitis C virus NS5A hyperphosphorylation by selective inhibition of cellular kinases activates viral RNA replication in cell culture. J Virol 2004; 78: 13306-13314.

102 Macdonald A, Harris M. Hepatitis C virus NS5A: tales of a promiscuous protein. J Gen Virol 2004; 85: 2485-2502.

103 Abe T, Kaname Y, Hamamoto I, Tsuda Y, Wen X, Taguwa S et al. Hepatitis $C$ virus nonstructural protein $5 \mathrm{~A}$ modulates the Toll-like receptor-MyD88-dependent signaling pathway in macrophage cell lines. J Virol 2007; 81: 8953-8966.

104 Gale MJ, Jr, Korth MJ, Tang NM, Tan SL, Hopkins DA, Dever TE et al. Evidence that hepatitis $C$ virus resistance to interferon is mediated through repression of the PKR protein kinase by the nonstructural 5A protein. Virology 1997; 230: 217-227.

105 Tan SL, Katze MG. How hepatitis C virus counteracts the interferon response: the jury is still out on NS5A. Virology 2001; 284: 1-12.

106 Gale M Jr, Blakely CM, Kwieciszewski B, Tan SL, Dossett M, Tang $\mathrm{NM}$ et al. Control of PKR protein kinase by hepatitis $C$ virus nonstructural 5A protein: molecular mechanisms of kinase regulation. Mol Cell Biol 1998; 18: 5208-5218.

107 Polyak SJ, Khabar KS, Paschal DM, Ezelle HJ, Duverlie G, Barber GN et al. Hepatitis $C$ virus nonstructural $5 \mathrm{~A}$ protein induces interleukin-8, leading to partial inhibition of the interferoninduced antiviral response. J Virol 2001; 75: 6095-6106.

108 Koo BC, McPoland P, Wagoner JP, Kane OJ, Lohmann V, Polyak SJ. Relationships between hepatitis $\mathrm{C}$ virus replication and CXCL-8 production in vitro. J Virol 2006; 80: 7885-7893.

109 Taguchi T, Nagano-Fujii M, Akutsu M, Kadoya H, Ohgimoto S, Ishido $S$ et al. Hepatitis $C$ virus NS5A protein interacts with $2^{\prime}, 5^{\prime}$ oligoadenylate synthetase and inhibits antiviral activity of IFN in an IFN sensitivity-determining region-independent manner. J Gen Virol 2004; 85: 959-969.

110 Han JQ, Barton DJ. Activation and evasion of the antiviral $2^{\prime}-5^{\prime}$ oligoadenylate synthetase/ribonuclease $L$ pathway by hepatitis $C$ virus mRNA. RNA 2002; 8: 512-525.

111 Ghosh AK, Majumder M, Steele R, Meyer K, Ray R, Ray RB. Hepatitis C virus NS5A protein protects against TNF-alpha mediated apoptotic cell death. Virus Res 2000; 67: 173-178.

112 Kanda T, Steele R, Ray R, Ray RB. Inhibition of intrahepatic gamma interferon production by hepatitis $C$ virus nonstructural protein $5 \mathrm{~A}$ in transgenic mice. J Virol 2009; 83: 8463-8469.

113 Miyasaka Y, Enomoto N, Kurosaki M, Sakamoto N, Kanazawa N, Kohashi $\mathrm{T}$ et al. Hepatitis $\mathrm{C}$ virus nonstructural protein $5 \mathrm{~A}$ inhibits 
tumor necrosis factor- $\alpha$-mediated apoptosis in Huh7 cells. $J$ Infect Dis 2003; 188: 1537-1544.

114 Christen V, Treves S, Duong FH, Heim MH. Activation of endoplasmic reticulum stress response by hepatitis viruses upregulates protein phosphatase 2A. Hepatology 2007; 46: 558565.

115 Janssens V, Goris J. Protein phosphatase 2A: a highly regulated family of serine/threonine phosphatases implicated in cell growth and signalling. Biochem J 2001; 353: 417-439.

116 Guergnon J, Godet AN, Galioot A, Falanga PB, Colle JH, Cayla X et al. PP2A targeting by viral proteins: a widespread biological strategy from DNA/RNA tumor viruses to HIV-1. Biochim Biophys Acta 2011; 1812: 1498-1507.

117 Duong FH, Filipowicz M, Tripodi M, La Monica N, Heim MH. Hepatitis $C$ virus inhibits interferon signaling through upregulation of protein phosphatase 2A. Gastroenterology 2004; 126: 263-277.

118 Duong FH, Christen V, Berke JM, Penna SH, Moradpour D, Heim $\mathrm{MH}$. Upregulation of protein phosphatase $2 \mathrm{Ac}$ by hepatitis $\mathrm{C}$ virus modulates NS3 helicase activity through inhibition of protein arginine methyltransferase 1. J Virol 2005; 79: 15342-15350.

119 Larner AC, Jonak G, Cheng YS, Korant B, Knight E, Darnell JE Jr. Transcriptional induction of two genes in human cells by $\beta$ interferon. Proc Natl Acad Sci USA 1984; 81: 6733-6737.

120 de Veer MJ, Holko M, Frevel M, Walker E, Der S, Paranjape JM et al. Functional classification of interferon-stimulated genes identified using microarrays. J Leukoc Biol 2001; 69: 912-920.

121 Li XL, Ezelle HJ, Hsi TY, Hassel BA. A central role for RNA in the induction and biological activities of type 1 interferons. Wiley Interdiscip Rev RNA 2011; 2: 58-78.

122 Jouan L, Chatel-Chaix L, Melancon P, Rodrigue-Gervais IG, Raymond VA, Selliah S et al. Targeted impairment of innate antiviral responses in the liver of chronic hepatitis $C$ patients. $J$ Hepatol 2012; 56: 70-77.

123 Kim MJ, Hwang SY, Imaizumi T, Yoo JY. Negative feedback regulation of RIG-I-mediated antiviral signaling by interferoninduced ISG15 conjugation. J Virol 2008; 82: 1474-1483.

124 Loo YM, Gale M Jr. Immune signaling by RIG-I-like receptors. Immunity 2011; 34: 680-692.

125 Wang Y, Ye L, Wang X, Li J, Song L, Ho W. Retinoic acid inducible gene-I (RIG-I) signaling of hepatic stellate cells inhibits hepatitis $C$ virus replication in hepatocytes. Innate Immun 2013; 19: 193202.

126 Phipps-Yonas H, Seto J, Sealfon SC, Moran TM, Fernandez-Sesma A. Interferon- $\beta$ pretreatment of conventional and plasmacytoid human dendritic cells enhances their activation by influenza virus. PLoS Pathog 2008; 4: e1000193.

127 Kolakofsky D, Kowalinski E, Cusack S. A structure-based model of RIG-I activation. RNA 2012; 18: 2118-2127.

128 Maelfait J, Beyaert R. Emerging role of ubiquitination in antiviral RIG-I signaling. Microbiol Mol Biol Rev 2012; 76: 33-45.

129 Miyashita M, Oshiumi H, Matsumoto M, Seya T. DDX60, a DEXD/H box helicase, is a novel antiviral factor promoting RIG-I-like receptor-mediated signaling. Mol Cell Biol 2011; 31: 3802-3819.

130 Marukian S, Andrus L, Sheahan TP, Jones CT, Charles ED, Ploss A et al. Hepatitis $C$ virus induces interferon- and interferon-stimulated genes in primary liver cultures. Hepatology 2011; 54: 1913-1923.

131 Taniguchi T, Ogasawara K, Takaoka A, Tanaka N. IRF family of transcription factors as regulators of host defense. Annu Rev Immunol 2001; 19: 623-655.

132 Pflugheber J, Fredericksen B, Sumpter R Jr, Wang C, Ware F, Sodora DL et al. Regulation of PKR and IRF-1 during hepatitis $C$ virus RNA replication. Proc Natl Acad Sci USA 2002; 99: 4650-4655.

133 Pine R. Constitutive expression of an ISGF2/IRF1 transgene leads to interferon-independent activation of interferon-inducible genes and resistance to virus infection. J Virol 1992; 66: 4470-4478.

134 Kanazawa N, Kurosaki M, Sakamoto N, Enomoto N, Itsui Y, Yamashiro $\mathrm{T}$ et al. Regulation of hepatitis $\mathrm{C}$ virus replication by interferon regulatory factor 1 . J Virol 2004; 78: 9713-9720.
135 Honda K, Yanai H, Negishi H, Asagiri M, Sato M, Mizutani T et al. IRF-7 is the master regulator of type-I interferon-dependent immune responses. Nature 2005; 434: 772-777.

136 Raychoudhuri A, Shrivastava S, Steele R, Dash S, Kanda T, Ray R et al. Hepatitis $C$ virus infection impairs IRF-7 translocation and Alpha interferon synthesis in immortalized human hepatocytes. $J$ Virol 2010; 84: 10991-10998.

137 Lazear HM, Lancaster A, Wilkins C, Suthar MS, Huang A, Vick SC et al. IRF-3, IRF-5, and IRF-7 coordinately regulate the type I IFN response in myeloid dendritic cells downstream of MAVS signaling. PLoS Pathog 2013; 9: e1003118.

138 Zhang T, Lin RT, Li Y, Douglas SD, Maxcey C, Ho C et al. Hepatitis C virus inhibits intracellular interferon alpha expression in human hepatic cell lines. Hepatology 2005; 42: 819-827.

139 Aly HH, Watashi K, Hijikata M, Kaneko H, Takada Y, Egawa $\mathrm{H}$ et al. Serum-derived hepatitis $\mathrm{C}$ virus infectivity in interferon regulatory factor-7-suppressed human primary hepatocytes. J Hepatol 2007; 46: $26-36$

140 Daffis S, Samuel MA, Suthar MS, Keller BC, Gale M Jr, Diamond MS. Interferon regulatory factor IRF-7 induces the antiviral alpha interferon response and protects against lethal West Nile virus infection. J Virol 2008; 82: 8465-8475.

141 Samuel CE. Antiviral actions of interferons. Clin Microbiol Rev 2001; 14: 778-809.

142 Garcia MA, Gil J, Ventoso I, Guerra S, Domingo E, Rivas C et al. Impact of protein kinase PKR in cell biology: from antiviral to antiproliferative action. Microbiol Mol Biol Rev 2006; 70: 10321060.

143 Dabo S, Meurs EF. dsRNA-dependent protein kinase PKR and its role in stress, signaling and HCV infection. Viruses 2012; 4: 2598-2635.

144 Kang JI, Kwon SN, Park SH, Kim YK, Choi SY, Kim JP et al. PKR protein kinase is activated by hepatitis $C$ virus and inhibits viral replication through translational control. Virus Res 2009; 142: $51-56$.

145 Rivas-Estilla AM, Svitkin Y, Lopez Lastra M, Hatzoglou M, Sherker A, Koromilas AE. PKR-dependent mechanisms of gene expression from a subgenomic hepatitis C virus clone. J Virol 2002; 76: 10637-10653.

146 Jiang D, Guo H, Xu C, Chang J, Gu B, Wang L et al. Identification of three interferon-inducible cellular enzymes that inhibit the replication of hepatitis C virus. J Virol 2008; 82: 1665-1678.

147 Wang C, Pflugheber J, Sumpter R Jr, Sodora DL, Hui D, Sen GC et al. Alpha interferon induces distinct translational control programs to suppress hepatitis C virus RNA replication. J Virol2003; 77: 38983912.

148 Taylor DR, Puig M, Darnell ME, Mihalik K, Feinstone SM. New antiviral pathway that mediates hepatitis $C$ virus replicon interferon sensitivity through ADAR1. J Virol 2005; 79: 62916298.

149 Arnaud N, Dabo S, Maillard P, Budkowska A, Kalliampakou KI, Mavromara $\mathrm{P}$ et al. Hepatitis $\mathrm{C}$ virus controls interferon production through PKR activation. PLoS One 2010; 5: e10575.

150 Ventoso I, Sanz MA, Molina S, Berlanga JJ, Carrasco L, Esteban M. Translational resistance of late alphavirus mRNA to elF2 $\alpha$ phosphorylation: a strategy to overcome the antiviral effect of protein kinase PKR. Genes Dev 2006; 20: 87-100.

151 Robert F, Kapp LD, Khan SN, Acker MG, Kolitz S, Kazemi S et al. Initiation of protein synthesis by hepatitis $C$ virus is refractory to reduced elF2.GTP.Met-tRNA(i)(Met) ternary complex availability. Mol Biol Cell 2006; 17: 4632-4644.

152 Shimoike T, McKenna SA, Lindhout DA, Puglisi JD. Translational insensitivity to potent activation of PKR by HCV IRES RNA. Antiviral Res 2009; 83: 228-237.

153 Karamichali E, Foka P, Tsitoura E, Kalliampakou K, Kazazi D, Karayiannis $\mathrm{P}$ et al. HCV NS5A co-operates with PKR in modulating HCV IRES-dependent translation. Infect Genet Evol 2014; 26C: 113-122.

154 Terenin IM, Dmitriev SE, Andreev DE, Shatsky IN. Eukaryotic translation initiation machinery can operate in a bacterial-like mode without elF2. Nat Struct Mol Biol 2008; 15: 836-841. 
155 Garaigorta U, Chisari FV. Hepatitis C virus blocks interferon effector function by inducing protein kinase R phosphorylation. Cell Host Microbe 2009; 6: 513-522.

156 Garaigorta U, Heim MH, Boyd B, Wieland S, Chisari FV. Hepatitis C virus $(\mathrm{HCV})$ induces formation of stress granules whose proteins regulate HCV RNA replication and virus assembly and egress. $J$ Virol 2012; 86: 11043-11056.

157 Beckham CJ, Parker R. P bodies, stress granules, and viral life cycles. Cell Host Microbe 2008; 3: 206-212.

158 Kedersha N, Anderson P. Stress granules: sites of mRNA triage that regulate mRNA stability and translatability. Biochem Soc Trans 2002; 30: 963-969.

159 Anderson P, Kedersha N. RNA granules. J Cell Biol 2006; 172: 803-808.

160 Anderson P, Kedersha N. Stress granules. Curr Biol 2009; 19: R397-398.

161 Buchan JR, Parker R. Eukaryotic stress granules: the ins and outs of translation. Mol Cell 2009; 36: 932-941.

162 Lloyd RE. Regulation of stress granules and P-bodies during RNA virus infection. Wiley Interdiscip Rev RNA 2013; 4: 317-331.

163 Reineke LC, Lloyd RE. Diversion of stress granules and P-bodies during viral infection. Virology 2013; 436: 255-267.

164 Ruggieri A, Dazert E, Metz P, Hofmann S, Bergeest JP, Mazur J et al. Dynamic oscillation of translation and stress granule formation mark the cellular response to virus infection. Cell Host Microbe 2012; 12 71-85.

165 Ariumi Y, Kuroki M, Kushima Y, Osugi K, Hijikata M, Maki M et al. Hepatitis $\mathrm{C}$ virus hijacks $\mathrm{P}$-body and stress granule components around lipid droplets. J Virol 2011; 85: 6882-6892.

166 Yi Z, Pan T, Wu X, Song W, Wang S, Xu Y et al. Hepatitis C virus coopts Ras-GTPase-activating protein-binding protein 1 for its genome replication. J Virol 2011; 85: 6996-7004.

167 Silverman $\mathrm{RH}$. Viral encounters with $2^{\prime}, 5^{\prime}$-oligoadenylate synthetase and RNase $L$ during the interferon antiviral response. $J$ Virol 2007; 81: 12720-12729.

168 Chakrabarti A, Jha BK, Silverman RH. New insights into the role of RNase L in innate immunity. J Interferon Cytokine Res 2011; 31: 49-57.

169 Kristiansen H, Gad HH, Eskildsen-Larsen S, Despres P, Hartmann $\mathrm{R}$. The oligoadenylate synthetase family: an ancient protein family with multiple antiviral activities. J Interferon Cytokine Res 2011; 31: 41-47.

170 Kwon YC, Kang JI, Hwang SB, Ahn BY. The ribonuclease Ldependent antiviral roles of human $2^{\prime}, 5^{\prime}$-oligoadenylate synthetase family members against hepatitis $C$ virus. FEBS Lett 2013; 587: 156-164.

171 Ishibashi M, Wakita T, Esumi M. 2',5'-Oligoadenylate synthetaselike gene highly induced by hepatitis $C$ virus infection in human liver is inhibitory to viral replication in vitro. Biochem Biophys Res Commun 2010; 392: 397-402.

172 Zhou Z, Wang N, Woodson SE, Dong Q, Wang J, Liang Y et al. Antiviral activities of ISG20 in positive-strand RNA virus infections. Virology 2011; 409: 175-188.

173 Degols G, Eldin P, Mechti N. ISG20, an actor of the innate immune response. Biochimie 2007; 89: 831-835.

174 Samuel CE. Adenosine deaminases acting on RNA (ADARs) are both antiviral and proviral. Virology 2011; 411: 180-193.

175 George CX, Gan Z, Liu Y, Samuel CE. Adenosine deaminases acting on RNA, RNA editing, and interferon action. J Interferon Cytokine Res 2011; 31: 99-117.

176 Toth AM, Li Z, Cattaneo R, Samuel CE. RNA-specific adenosine deaminase ADAR1 suppresses measles virus-induced apoptosis and activation of protein kinase PKR. J Biol Chem 2009; 284: 29350-29356.

177 George CX, Wagner MV, Samuel CE. Expression of interferoninducible RNA adenosine deaminase ADAR1 during pathogen infection and mouse embryo development involves tissueselective promoter utilization and alternative splicing. J Biol Chem 2005; 280: 15020-15028.
178 Polson AG, Bass BL, Casey JL. RNA editing of hepatitis delta virus antigenome by dsRNA-adenosine deaminase. Nature 1996; 380 454-456.

179 Luo GX, Chao M, Hsieh SY, Sureau C, Nishikura K, Taylor J. A specific base transition occurs on replicating hepatitis delta virus RNA. J Virol 1990; 64: 1021-1027.

180 Casey JL. RNA editing in hepatitis delta virus. Curr Top Microbiol Immunol 2006; 307: 67-89.

181 Brass AL, Huang IC, Benita Y, John SP, Krishnan MN, Feeley EM et al. The IFITM proteins mediate cellular resistance to influenza $A$ H1N1 virus, West Nile virus, and dengue virus. Cell 2009; 139: 1243-1254.

182 Bailey CC, Huang IC, Kam C, Farzan M. Ifitm3 limits the severity of acute influenza in mice. PLoS Pathog 2012; 8: e1002909.

183 Diamond MS, Farzan M. The broad-spectrum antiviral functions of IFIT and IFITM proteins. Nat Rev Immunol 2013; 13: 46-57.

184 Perreira JM, Chin CR, Feeley EM, Brass AL. IFITMs restrict the replication of multiple pathogenic viruses. J Mol Biol 2013; 425: 4937-4955.

185 Huang IC, Bailey CC, Weyer JL, Radoshitzky SR, Becker MM, Chiang $\mathrm{JJ}$ et al. Distinct patterns of IFITM-mediated restriction of filoviruses, SARS coronavirus, and influenza A virus. PLoS Pathog 2011; 7: e1001258.

186 Wilkins C, Woodward J, Lau DT, Barnes A, Joyce M, McFarlane N et al. IFITM 1 is a tight junction protein that inhibits hepatitis $C$ virus entry. Hepatology 2013; 57: 461-469.

187 Feeley EM, Sims JS, John SP, Chin CR, Pertel T, Chen LM et al. IFITM3 inhibits influenza A virus infection by preventing cytosolic entry. PLoS Pathog 2011; 7: e1002337.

188 Amini-Bavil-Olyaee S, Choi YJ, Lee JH, Shi M, Huang IC, Farzan M et al. The antiviral effector IFITM3 disrupts intracellular cholesterol homeostasis to block viral entry. Cell Host Microbe 2013; 13: 452464.

189 Mudhasani R, Tran JP, Retterer C, Radoshitzky SR, Kota KP, Altamura LA et al. IFITM-2 and IFITM-3 but not IFITM-1 restrict Rift Valley fever virus. J Virol 2013; 87: 8451-8464.

190 John SP, Chin CR, Perreira JM, Feeley EM, Aker AM, Savidis G et al. The CD225 domain of IFITM3 is required for both IFITM protein association and inhibition of influenza $A$ virus and dengue virus replication. J Virol 2013; 87: 7837-7852.

191 Pichlmair A, Lassnig C, Eberle CA, Gorna MW, Baumann CL, Burkard TR et al. IFIT1 is an antiviral protein that recognizes $5^{\prime}$ triphosphate RNA. Nat Immunol 2011; 12: 624-630.

192 Liu XY, Chen W, Wei B, Shan YF, Wang C. IFN-induced TPR protein IFIT3 potentiates antiviral signaling by bridging MAVS and TBK1. $J$ Immunol 2011; 187: 2559-2568.

193 Manes S, del Real G, Martinez AC. Pathogens: raft hijackers. Nat Rev Immunol 2003; 3: 557-568.

194 Schroeder C. Cholesterol-binding viral proteins in virus entry and morphogenesis. Subcell Biochem 2010; 51: 77-108.

195 Raychaudhuri S, Prinz WA. The diverse functions of oxysterolbinding proteins. Annu Rev Cell Dev Biol 2010; 26: 157-177.

196 Holthuis JC, Levine TP. Lipid traffic: floppy drives and a superhighway. Nat Rev Mol Cell Biol 2005; 6: 209-220.

197 Levine T. Short-range intracellular trafficking of small molecules across endoplasmic reticulum junctions. Trends Cell Biol 2004; 14: 483-490.

198 Carette JE, Raaben M, Wong AC, Herbert AS, Obernosterer G, Mulherkar $\mathrm{N}$ et al. Ebola virus entry requires the cholesterol transporter Niemann-Pick C1. Nature 2011; 477: 340-343.

199 Li K, Markosyan RM, Zheng YM, Golfetto O, Bungart B, Li M et al. IFITM proteins restrict viral membrane hemifusion. PLoS Pathog 2013; 9: e1003124.

200 Raychoudhuri A, Shrivastava S, Steele R, Kim H, Ray R, Ray RB. ISG56 and IFITM1 proteins inhibit hepatitis $C$ virus replication. $J$ Virol 2011; 85: 12881-12889.

201 D'Andrea LD, Regan L. TPR proteins: the versatile helix. Trends Biochem Sci 2003; 28: 655-662.

202 Fensterl V, Sen GC. The ISG56/IFIT1 gene family. J Interferon Cytokine Res 2011; 31: 71-78. 
203 Li Y, Li C, Xue P, Zhong B, Mao AP, Ran Y et al. ISG56 is a negativefeedback regulator of virus-triggered signaling and cellular antiviral response. Proc Natl Acad Sci USA 2009; 106: 7945-7950.

204 Daffis S, Szretter KJ, Schriewer J, Li J, Youn S, Errett J et al. 2'-O methylation of the viral mRNA cap evades host restriction by IFIT family members. Nature 2010; 468: 452-456.

205 Wacher C, Muller M, Hofer MJ, Getts DR, Zabaras R, Ousman SS et al. Coordinated regulation and widespread cellular expression of interferon-stimulated genes (ISG) ISG-49, ISG-54, and ISG-56 in the central nervous system after infection with distinct viruses. $J$ Virol 2007; 81: 860-871.

206 Ciechanover A. Tracing the history of the ubiquitin proteolytic system: the pioneering article. Biochem Biophys Res Commun 2009; 387: 1-10.

207 Komander D, Rape M. The ubiquitin code. Annu Rev Biochem 2012; 81: 203-229.

208 Everett RD, Boutell C, Hale BG. Interplay between viruses and host sumoylation pathways. Nat Rev Microbiol 2013; 11: 400-411.

209 Rajsbaum R, Garcia-Sastre A. Viral evasion mechanisms of early antiviral responses involving regulation of ubiquitin pathways. Trends Microbiol 2013; 21: 421-429.

210 Chen L, Li S, Li Y, Duan X, Liu B, McGilvray I. Ubiquitin-like protein modifiers and their potential for antiviral and anti-HCV therapy. Expert Rev Proteomics 2013; 10: 275-287.

211 Jeon YJ, Yoo HM, Chung CH. ISG15 and immune diseases. Biochim Biophys Acta 2010; 1802: 485-496.

212 Zhao C, Denison C, Huibregtse JM, Gygi S, Krug RM. Human ISG15 conjugation targets both IFN-induced and constitutively expressed proteins functioning in diverse cellular pathways. Proc Natl Acad Sci USA 2005; 102: 10200-10205.

213 Giannakopoulos NV, Luo JK, Papov V, Zou W, Lenschow DJ, Jacobs BS et al. Proteomic identification of proteins conjugated to ISG15 in mouse and human cells. Biochem Biophys Res Commun 2005; 336: 496-506.

214 Morales DJ, Lenschow DJ. The antiviral activities of ISG15. J Mol Biol 2013; 425: 4995-5008.

215 Lu G, Reinert JT, Pitha-Rowe I, Okumura A, Kellum M, Knobeloch $\mathrm{KP}$ et al. ISG15 enhances the innate antiviral response by inhibition of IRF-3 degradation. Cell Mol Biol (Noisy-le-grand) 2006; 52: 29 41.

216 Shi HX, Yang K, Liu X, Liu XY, Wei B, Shan YF et al. Positive regulation of interferon regulatory factor 3 activation by Herc5 via ISG15 modification. Mol Cell Biol 2010; 30: 2424-2436.

217 Okumura F, Okumura AJ, Uematsu K, Hatakeyama S, Zhang DE, Kamura T. Activation of double-stranded RNA-activated protein kinase (PKR) by interferon-stimulated gene 15 (ISG15) modification down-regulates protein translation. J Biol Chem 2013; 288: 2839-2847.

218 Lenschow DJ, Giannakopoulos NV, Gunn LJ, Johnston C, O'Guin AK, Schmidt RE et al. Identification of interferon-stimulated gene 15 as an antiviral molecule during Sindbis virus infection in vivo. J Virol 2005; 79: 13974-13983.

219 Lenschow DJ, Lai C, Frias-Staheli N, Giannakopoulos NV, Lutz A, Wolff $T$ et al. IFN-stimulated gene 15 functions as a critical antiviral molecule against influenza, herpes, and Sindbis viruses. Proc Natl Acad Sci USA 2007; 104: 1371-1376.

220 Chen L, Sun J, Meng L, Heathcote J, Edwards AM, McGilvray ID. ISG15, a ubiquitin-like interferon-stimulated gene, promotes hepatitis $C$ virus production in vitro: implications for chronic infection and response to treatment. J Gen Virol 2010; 91: 382388.

221 Arnaud N, Dabo S, Akazawa D, Fukasawa M, Shinkai-Ouchi F, Hugon $\mathrm{J}$ et al. Hepatitis $C$ virus reveals a novel early control in acute immune response. PLoS Pathog 2011; 7: e1002289.

222 Malakhov MP, Malakhova OA, Kim KI, Ritchie KJ, Zhang DE. UBP43 (USP18) specifically removes ISG15 from conjugated proteins. J Biol Chem 2002; 277: 9976-9981.

223 Malakhova OA, Kim KI, Luo JK, Zou W, Kumar KG, Fuchs SY et al. UBP43 is a novel regulator of interferon signaling independent of its ISG15 isopeptidase activity. EMBO J 2006; 25: 2358-2367.
$224 \mathrm{Kim} \mathrm{JH}$, Luo JK, Zhang DE. The level of hepatitis B virus replication is not affected by protein ISG15 modification but is reduced by inhibition of UBP43 (USP18) expression. J Immunol 2008; 181: 6467-6472.

225 Malakhova OA, Zhang DE. ISG15 inhibits Nedd4 ubiquitin E3 activity and enhances the innate antiviral response. J Biol Chem 2008; 283: 8783-8787.

226 Randall G, Chen L, Panis M, Fischer AK, Lindenbach BD, Sun J et al. Silencing of USP18 potentiates the antiviral activity of interferon against hepatitis C virus infection. Gastroenterology 2006; 131: 1584-1591.

227 Murray EJ, Burden F, Horscroft N, Smith-Burchnell C, Westby M. Knockdown of USP18 increases $\alpha 2$ a interferon signaling and induction of interferon-stimulating genes but does not increase antiviral activity in Huh7 cells. Antimicrob Agents Chemother 2011; 55: 4311-4319.

228 Asahina Y, Izumi N, Hirayama I, Tanaka T, Sato M, Yasui Y et al. Potential relevance of cytoplasmic viral sensors and related regulators involving innate immunity in antiviral response. Gastroenterology 2008; 134: 1396-1405.

229 Sarasin-Filipowicz M, Oakeley EJ, Duong FH, Christen V, Terracciano L, Filipowicz $W$ et al. Interferon signaling and treatment outcome in chronic hepatitis C. Proc Natl Acad Sci USA 2008; 105: 7034-7039.

230 Chen L, Li S, McGilvray I. The ISG15/USP18 ubiquitin-like pathway (ISGylation system) in hepatitis $C$ virus infection and resistance to interferon therapy. Int J Biochem Cell Biol 2011; 43: 1427-1431.

231 Seo JY, Yaneva R, Cresswell P. Viperin: a multifunctional, interferon-inducible protein that regulates virus replication. Cell Host Microbe 2011; 10: 534-539.

232 Helbig KJ, Beard MR. The role of viperin in the innate antiviral response. J Mol Biol 2014; 426: 1210-1219.

233 Fitzgerald KA. The interferon inducible gene: viperin. J Interferon Cytokine Res 2011; 31: 131-135.

234 Mattijssen S, Pruijn GJ. Viperin, a key player in the antiviral response. Microbes Infect 2012; 14: 419-426.

235 Wang $X$, Hinson ER, Cresswell P. The interferon-inducible protein viperin inhibits influenza virus release by perturbing lipid rafts. Cell Host Microbe 2007; 2: 96-105.

236 Nasr N, Maddocks S, Turville SG, Harman AN, Woolger N, Helbig KJ et al. HIV-1 infection of human macrophages directly induces viperin which inhibits viral production. Blood 2012; 120: 778788.

237 Chan YL, Chang TH, Liao CL, Lin YL. The cellular antiviral protein viperin is attenuated by proteasome-mediated protein degradation in Japanese encephalitis virus-infected cells. J Virol 2008; 82: 10455-10464.

238 Seo JY, Yaneva R, Hinson ER, Cresswell P. Human cytomegalovirus directly induces the antiviral protein viperin to enhance infectivity. Science 2011; 332: 1093-1097.

239 Helbig KJ, Lau DT, Semendric L, Harley HA, Beard MR. Analysis of ISG expression in chronic hepatitis $C$ identifies viperin as a potential antiviral effector. Hepatology 2005; 42: 702-710.

240 Helbig KJ, Eyre NS, Yip E, Narayana S, Li K, Fiches G et al. The antiviral protein viperin inhibits hepatitis $C$ virus replication via interaction with nonstructural protein 5A. Hepatology 2011; 54: 1506-1517.

241 Wang S, Wu X, Pan T, Song W, Wang Y, Zhang F et al. Viperin inhibits hepatitis $C$ virus replication by interfering with binding of NS5A to host protein hVAP-33. J Gen Virol 2012; 93: 83-92.

242 Liu SY, Aliyari R, Chikere K, Li G, Marsden MD, Smith JK et al. Interferon-inducible cholesterol-25-hydroxylase broadly inhibits viral entry by production of 25-hydroxycholesterol. Immunity 2013; 38: 92-105.

243 Kielian M, Rey FA. Virus membrane-fusion proteins: more than one way to make a hairpin. Nat Rev Microbiol 2006; 4: 67-76.

244 Vaney MC, Rey FA. Class II enveloped viruses. Cell Microbio/2011; 13: 1451-1459.

245 Brodsky LI, Wahed AS, Li J, Tavis JE, Tsukahara T, Taylor MW. A novel unsupervised method to identify genes important in the anti- 
viral response: application to interferon/ribavirin in hepatitis $C$ patients. PLoS One 2007; 2: e584.

246 Metz P, Dazert E, Ruggieri A, Mazur J, Kaderali L, Kaul A et al. Identification of type I and type II interferon-induced effectors controlling hepatitis C virus replication. Hepatology 2012; 56 : 2082-2093.

247 Fusco DN, Brisac C, John SP, Huang YW, Chin CR, Xie T et al. A genetic screen identifies interferon- $\alpha$ effector genes required to suppress hepatitis C virus replication. Gastroenterology 2013; 144: 1438-1349.

248 Zhao H, Lin W, Kumthip K, Cheng D, Fusco DN, Hofmann 0 et al. A functional genomic screen reveals novel host genes that mediate interferon-alpha's effects against hepatitis C virus. J Hepatol 2012; 56: 326-333.

249 Jurica MS, Moore MJ. Pre-mRNA splicing: awash in a sea of proteins. Mol Cel/ 2003; 12: 5-14.

250 Li Q, Brass AL, Ng A, Hu Z, Xavier RJ, Liang TJ et al. A genome-wide genetic screen for host factors required for hepatitis $C$ virus propagation. Proc Natl Acad Sci USA 2009; 106: 16410-16415.

251 Li Q, Pene V, Krishnamurthy S, Cha H, Liang TJ. Hepatitis C virus infection activates an innate pathway involving IKK- $\alpha$ in lipogenesis and viral assembly. Nat Med 2013; 19: 722-729.

252 Dansako H, Yamane D, Welsch C, McGivern DR, Hu F, Kato N et al. Class A scavenger receptor 1 (MSR 1 ) restricts hepatitis $C$ virus replication by mediating Toll-like receptor 3 recognition of viral RNAs produced in neighboring cells. PLoS Pathog 2013; 9: e1003345.

253 Andersson U, Tracey KJ. HMGB1 is a therapeutic target for sterile inflammation and infection. Annu Rev Immunol 2011; 29: 139162.

254 Scaffidi P, Misteli T, Bianchi ME. Release of chromatin protein HMGB1 by necrotic cells triggers inflammation. Nature 2002; 418: 191-195.

255 Tang D, Kang R, Zeh HJ 3rd, Lotze MT. High-mobility group box 1, oxidative stress, and disease. Antioxid Redox Signal 2011; 14: 1315-1335.

256 Gong G, Waris G, Tanveer R, Siddiqui A. Human hepatitis C virus NS5A protein alters intracellular calcium levels, induces oxidative stress, and activates STAT-3 and NF-кB. Proc Natl Acad Sci USA 2001; 98: 9599-9604.

257 Korenaga M, Wang T, Li Y, Showalter LA, Chan T, Sun J et al. Hepatitis $C$ virus core protein inhibits mitochondrial electron transport and increases reactive oxygen species (ROS) production. J Biol Chem 2005; 280: 37481-37488.

258 Piccoli C, Scrima R, Quarato G, D’Aprile A, Ripoli M, Lecce L et al. Hepatitis $C$ virus protein expression causes calcium-mediated mitochondrial bioenergetic dysfunction and nitro-oxidative stress. Hepatology 2007; 46: 58-65.

259 Jung JH, Park JH, Jee MH, Keum SJ, Cho MS, Yoon SK et al. Hepatitis $C$ virus infection is blocked by HMGB1 released from virus-infected cells. J Virol 2011; 85: 9359-9368.

260 Takeuchi 0 , Akira S. Pattern recognition receptors and inflammation. Cell 2010; 140: 805-820.

261 Cheng BQ, Jia CQ, Liu CT, Lu XF, Zhong N, Zhang ZL et al. Serum high mobility group box chromosomal protein 1 is associated with clinicopathologic features in patients with hepatocellular carcinoma. Dig Liver Dis 2008; 40: 446-452.

262 Mizushima N, Levine B, Cuervo AM, Klionsky DJ. Autophagy fights disease through cellular self-digestion. Nature 2008; 451: 10691075.

263 Maiuri MC, Zalckvar E, Kimchi A, Kroemer G. Self-eating and selfkilling: crosstalk between autophagy and apoptosis. Nat Rev Mol Cell Biol 2007; 8: 741-752.

264 Mizushima N. Autophagy: process and function. Genes Dev 2007; 21: 2861-2873.

265 Klionsky DJ. Autophagy: from phenomenology to molecular understanding in less than a decade. Nat Rev Mol Cell Biol 2007; 8: 931-937.

266 Kroemer G, Marino G, Levine B. Autophagy and the integrated stress response. Molecular Cell 2010; 40: 280-293.
267 Orvedahl A, MacPherson S, Sumpter R Jr, Talloczy Z, Zou Z, Levine B. Autophagy protects against Sindbis virus infection of the central nervous system. Cell Host Microbe 2010; 7: 115-127.

268 Shelly S, Lukinova N, Bambina S, Berman A, Cherry S. Autophagy is an essential component of Drosophila immunity against vesicular stomatitis virus. Immunity 2009; 30: 588-598.

269 Munz C. Enhancing immunity through autophagy. Annu Rev Immunol 2009; 27: 423-449.

270 Orvedahl A, Levine B. Eating the enemy within: autophagy in infectious diseases. Cell Death Differ 2009; 16: 57-69.

271 Virgin HW, Levine B. Autophagy genes in immunity. Nat Immunol 2009; 10: 461-470.

272 Deretic V, Levine B. Autophagy, immunity, and microbial adaptations. Cell Host Microbe 2009; 5: 527-549.

273 Levine B, Mizushima N, Virgin HW. Autophagy in immunity and inflammation. Nature 2011; 469: 323-335.

274 Sir D, Chen WL, Choi J, Wakita T, Yen TS, Ou JH. Induction of incomplete autophagic response by hepatitis $\mathrm{C}$ virus via the unfolded protein response. Hepatology 2008; 48: 1054-1061.

275 Dreux M, Gastaminza P, Wieland SF, Chisari FV. The autophagy machinery is required to initiate hepatitis $C$ virus replication. Proc Natl Acad Sci USA 2009; 106: 14046-14051.

276 Tanida I, Fukasawa M, Ueno T, Kominami E, Wakita T, Hanada K. Knockdown of autophagy-related gene decreases the production of infectious hepatitis C virus particles. Autophagy 2009; 5: 937945.

277 Ke PY, Chen SS. Activation of the unfolded protein response and autophagy after hepatitis $C$ virus infection suppresses innate antiviral immunity in vitro. J Clin Invest 2011; 121: 37-56.

278 Huang H, Kang R, Wang J, Luo G, Yang W, Zhao Z. Hepatitis C virus inhibits AKT-tuberous sclerosis complex (TSC), the mechanistic target of rapamycin (MTOR) pathway, through endoplasmic reticulum stress to induce autophagy. Autophagy 2013; 9: 175-195.

279 Shrivastava S, Bhanja Chowdhury J, Steele R, Ray R, Ray RB. Hepatitis $C$ virus upregulates Beclin 1 for induction of autophagy and activates mTOR signaling. J Virol 2012; 86: 8705-8712.

280 Shrivastava S, Raychoudhuri A, Steele R, Ray R, Ray RB. Knockdown of autophagy enhances the innate immune response in hepatitis C virus-infected hepatocytes. Hepatology 2011; 53 406-414.

281 Kim SJ, Syed GH, Siddiqui A. Hepatitis C Virus induces the mitochondrial translocation of Parkin and subsequent mitophagy. PloS Pathog 2013; 9: e1003285.

282 Gregoire IP, Rabourdin-Combe C, Faure M. Autophagy and RNA virus interactomes reveal IRGM as a common target. Autophagy 2012; 8: 1136-1137.

283 Sonkoly E, Stahle M, Pivarcsi A. MicroRNAs and immunity: novel players in the regulation of normal immune function and inflammation. Semin Cancer Biol 2008; 18: 131-140.

284 Jackson RJ, Standart N. How do microRNAs regulate gene expression? Sci STKE 2007; 2007: re1.

285 Zhou R, O'Hara SP, Chen XM. MicroRNA regulation of innate immune responses in epithelial cells. Cell Mol Immunol 2011; 8: 371-379.

286 Gupta P, Cairns MJ, Saksena NK. Regulation of gene expression by microRNA in HCV infection and HCV-mediated hepatocellular carcinoma. Virol J 2014; 11: 64.

287 Chen Y, Chen J, Wang H, Shi J, Wu K, Liu S et al. HCV-induced miR21 contributes to evasion of host immune system by targeting MyD88 and IRAK1. PLoS Pathog 2013; 9: e1003248.

This work is licensed under a Creative Commons Attribution-NonCommercial-NoDerivs 3.0 Unported License. The images or other third party material in this article are included in the article's Creative Commons license, unless indicated otherwise in the credit line; if the material is not included under the Creative Commons license, users will need to obtain permission from the license holder to reproduce the material. To view a copy of this license, visit http://creativecommons.org/licenses/by-nc-nd/3.0/ 